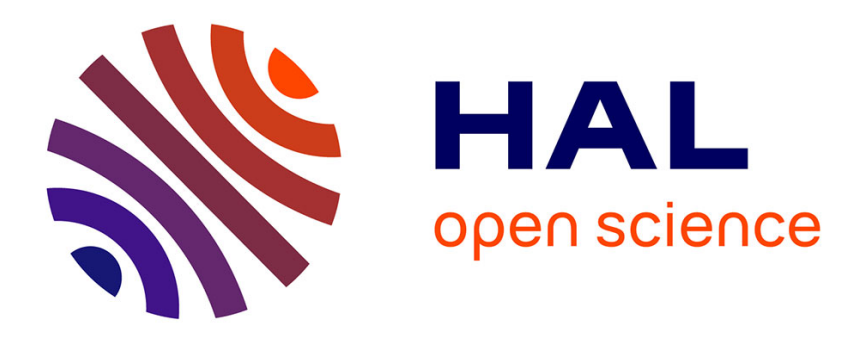

\title{
Hydrogel-Colloid Composite Bioinks for Targeted Tissue-Printing
}

Raphaël Michel, Rachel Auzély-Velty

\section{To cite this version:}

Raphaël Michel, Rachel Auzély-Velty. Hydrogel-Colloid Composite Bioinks for Targeted TissuePrinting. Biomacromolecules, 2020, 21 (8), pp.2949-2965. 10.1021/acs.biomac.0c00305 . hal03371536

\section{HAL Id: hal-03371536 https://hal.science/hal-03371536}

Submitted on 8 Oct 2021

HAL is a multi-disciplinary open access archive for the deposit and dissemination of scientific research documents, whether they are published or not. The documents may come from teaching and research institutions in France or abroad, or from public or private research centers.
L'archive ouverte pluridisciplinaire HAL, est destinée au dépôt et à la diffusion de documents scientifiques de niveau recherche, publiés ou non, émanant des établissements d'enseignement et de recherche français ou étrangers, des laboratoires publics ou privés. 


\section{Hydrogel-colloid composite bioinks for targeted tissue-printing}

Raphaël Michel* and Rachel Auzély-Velty*

Université Grenoble Alpes, Centre de Recherches sur les Macromolécules Végétales

(CERMAV)-CNRS, 601, rue de la Chimie, BP 53, 38041 Grenoble Cedex 9 (France)

KEYWORDS: bioprinting, bioinks, colloids, hydrogel, polymer, tissue engineering

ABSTRACT: The development of extrusion-based bioprinting for tissue engineering is conditioned by the design of bioinks displaying adequate printability, shape stability and postprinting bioactivity. In this context, simple bioink formulations, made of cells supported by a polymer matrix, often lack the necessary versatility. To address this issue, intense research work has been focused on introducing colloidal particles into the ink formulation. By creating weak crosslinks between polymer chains, added particles modify the rheology and mechanical behavior of bioinks to improve their printability and structural integrity. Additionally, nano- and microscopic particles display composition- and structure-specific properties that can affect the cellular behavior and enhance the formation of tissue within the printed material. This review offers a comprehensive picture of the role of colloids in bioprinting from a physicochemical and biological perspective. As such, it provides guidance on devising adaptable bioinks for the fabrication of biomimetic tissues. 


\section{INTRODUCTION}

3D-bioprinting consists in the controlled deposition (printing) of cell-laden materials to fabricate biomimetic tissues. ${ }^{1-5}$ In comparison to other strategies employed in tissue engineering (molding, porous scaffold), bioprinting is a simple, time and cost-effective process that leads to tissue constructs with a larger range of resolutions, a more precise control over cell positioning and a higher degree of repeatability. ${ }^{1}$ Different bioprinting techniques are available such as inkjet, laserassisted or extrusion-based deposition. 1, 3, 6,7 Among these technologies, extrusion-based bioprinting is the most commonly used as it combines simplicity, affordability and versatility. By this method, materials with a broad range of viscosities and a high cell density can be printed into large-scale 3D tissue contructs. ${ }^{7-10}$

Bioinks for extrusion printing contain living cells embedded either in a polymer solution or in weakly crosslinked hydrogel matrix. ${ }^{10,11}$ Polymers selected for bioink formulations are, in the vast majority, biomacromolecules such as proteins (collagen, gelatin) or polysaccharides (alginate, hyaluronic acid, chitosan, gellan). During the printing process, the bioink is forced to flow through a nozzle and deposited on a platform upon application of pneumatic or mechanical pressure (see Figure $1-\mathrm{A}){ }^{7}$

The rheological behavior of the bioink plays a crucial role in its printability. In particular, the ink viscosity is important since a low viscosity leads to the spreading of the ink after extrusion thereby reducing the shape fidelity. Additionally, cells encapsulated in low viscosity bioinks have the tendency to sediment rapidly yielding inhomogeneous cell distribution in the printed material. ${ }^{12}$ Conversely, highly viscous bioinks induce nozzle clogging and increase shear stress during printing, which dramatically damage cells. ${ }^{13}$ To avoid these issues, appropriate bioinks must display a non-Newtonian behavior. ${ }^{9}, 11$ They should present shear-thinning properties, meaning 
that their viscosity would decrease upon increasing shear rate (Figure 1-(i)). In such systems, the polymer chains align along the flow direction during printing (Figure 1-A) which reduces shear stress and guarantees both the facile deposition of the ink and the survival of cells. Ideally, a bioink must also exhibit a suitable yield stress, which is the minimum stress needed to initiate flow (Figure 1-(ii) \& (iii)). ${ }^{14}$ Bioinks combining shear thinning properties and appropriate yield stress values display a flow behavior in which the shear stress and shear thinning response are confined at the edge of the printing nozzle while the central part of the ink is relatively undeformed and extruded as a viscoelastic filament. ${ }^{11}$ Such behavior not only contributes to the shape fidelity of the printed object but also shields encapsulated cells from shear during extrusion by creating a plug flow. ${ }^{9,15,}$ ${ }^{16}$ Another key rheological parameter of shear-thinning bioinks is the time-dependent recovery of their mechanical properties after extrusion. Indeed, in order to prevent spreading and achieve shape fidelity, the ink must undergo a rapid structural transition to regain its original viscosity in the absence of stress. This thixotropic behavior is referred to as shear recovery in this manuscript (Figure 1-(iv)). ${ }^{8,9,11,17}$

After printing and for the purpose of immobilizing the printing object and guaranteeing its longterm shape stability, the polymer matrix of the bioink is permanently cross-linked (Figure 1-B). This can be performed either by chemical ${ }^{18}$ or strong physical crosslinking. ${ }^{19,20}$ The so-obtained cell-laden hydrogel should possess a mechanical response matching the targeted tissue (Figure 1(v)) and a limited swelling behavior in culture media (Figure 1-(vi)).

In the last five years, colloids consisting of nano- or microscopic particles of various shape (spheres, platelets, crystals, rods, fibers, etc.) and composition (inorganic or polymer-based) were included in bioink formulations (Figure 2-A) for extrusion bioprinting. Colloidal particles interact with both the polymer matrix and the cells contained in the ink thereby affecting not only the 
mechanical behavior of the ink (rheology, stiffness, etc.), but also the proliferation and differentiation of the encapsulated cells. More precisely, particles create weak physical crosslinks within the polymer matrix (Figure 2-B) which significantly modify its rheology and can thus serve to improve the bioink printability. Besides, embedded particles also have the ability to strengthen hydrogel networks ${ }^{21-24}$ (Figure 2-C) which can be conveniently used to adjust the mechanical properties of printed biomaterials after crosslinking. Finally, a wide variety of colloids (hydroxyapatite, cellulose, silica, clay, graphene, etc.) interact positively with cells (Figure 2-D) and display specific functionalities (antioxidant properties, drug release, electroactivity - Figure 2E) that can contribute to guide and enhance the growth of synthetic tissue. ${ }^{25,26}$ For all these reasons, colloidal materials have a central role to play in the development of original bioinks with optimized printability yielding complex tissue constructs. 
A
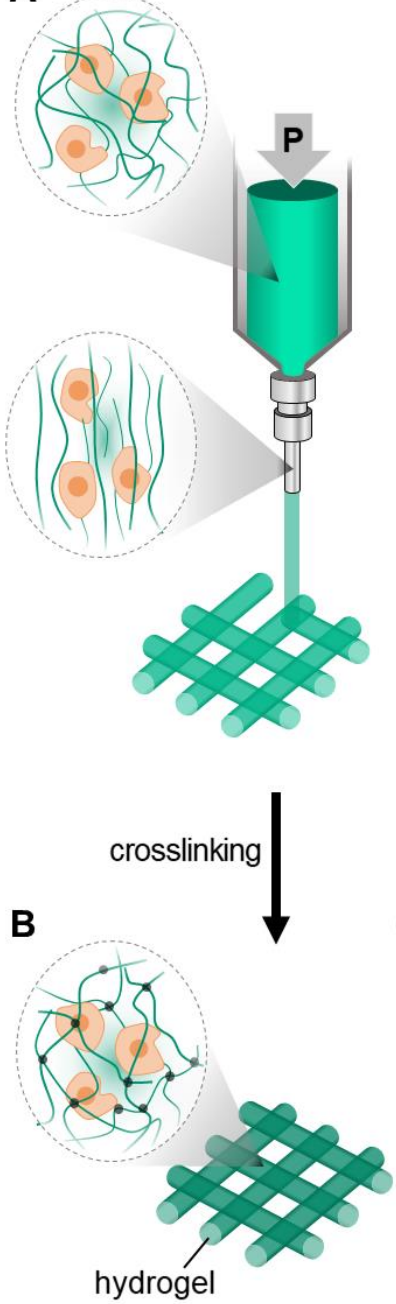

Bioinkrheological parameters
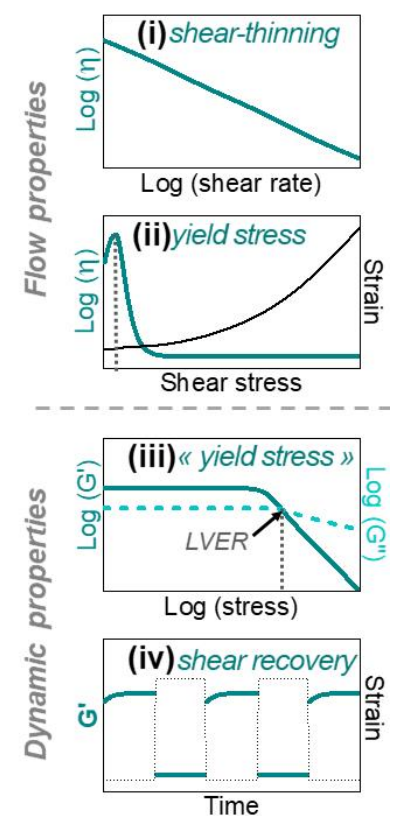

Characteristics of printed hydrogels

(v)

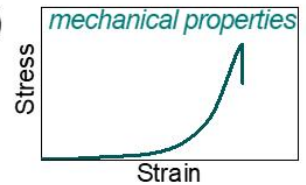

(vi)

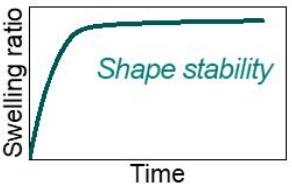

Figure 1: Schematic representation of the extrusion (A) and crosslinking step (B) of the bioprinting process. Summary of necessary experiments to characterize the key rheological parameters of bioinks and the mechanical and structural characteristics of printed hydrogels. (i) shear-thinning behavior; (ii) yield stress; (iii) limit of the linear viscoelastic region (LVER) which delivers information on the yield stress in an oscillatory regime; (iv) shear recovery; (v) mechanical properties obtained by compressive or tensile tests on printed hydrogels; (vi) shape stability as defined by the equilibrium swelling of the hydrogel. In this figure, $\eta$ stands for the viscosity and G' and G' for the storage and loss modulus of the bioink, respectively. 
Recent reviews have described general advances in the field of bioprinting ${ }^{10,27}$ and reinforcement strategies for bioinks. ${ }^{11}$ Some have presented acellular composite systems for 3D printing of biocompatible materials ${ }^{28}$ and others have discussed the interest of one specific class of colloids in bioinks (cellulose ${ }^{29,30}$ nanoclay $^{31}$ ) or the potential of bioprinting for one particular tissue type. ${ }^{31-35}$ But to the best of our knowledge, there is no published review on composite bioinks which addresses both the physicochemical tailoring of bioinks by colloids as well as their influence on the proliferation and differentiation of cells in printed tissues. To fulfill this need, this manuscript offers an overview of the recent experimental advances on composite bioinks for extrusion printing by describing (i) the multifaceted influence of embedded colloids on the rheology of bioinks and the mechanical properties of printed hydrogels and (ii) the crucial role of the colloidal materials in guiding the cell fate and introducing new functionalities to engineer sophisticated tissues. Additionally, insights and methods to select the appropriate colloidal materials in the formulation of composite bioinks are provided. Finally, the last section of this review describes remaining challenges and interesting prospects such as the potential of composite systems for 4D bioprinting and the formulation of bioinks containing multiple colloidal species for the printing of multifunctional biomimetic tissues. 


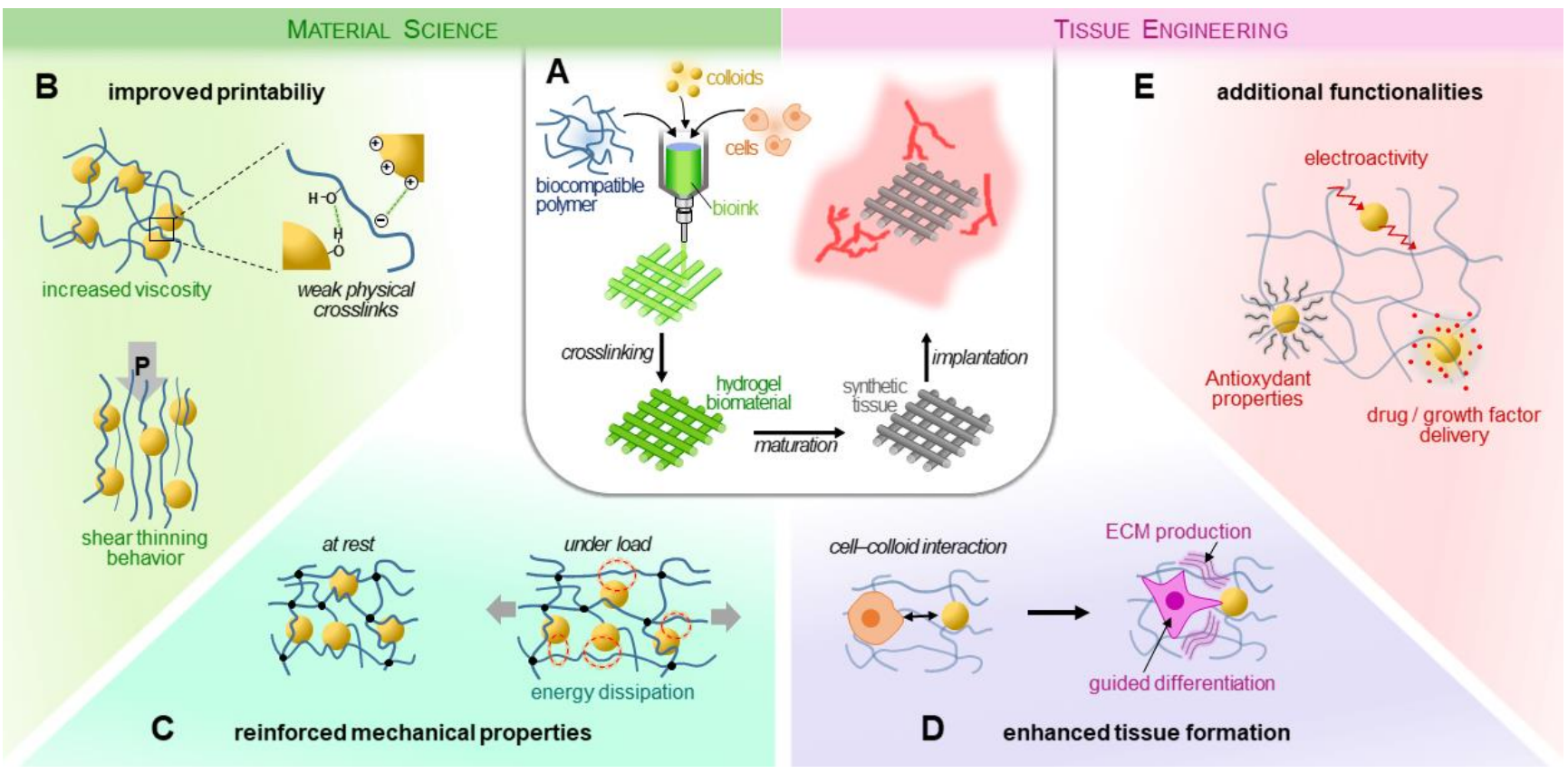

Figure 2: Schematic drawings depicting the role of colloids in bioinks. (A) The different steps of the fabrication of a tissue construct upon bioprinting of a composite bioink. (B) The influence of colloids on the structure and rheology of the polymer matrix before and during printing. (C) The effect of the embedded particles on the mechanical response of the printed hydrogels. (D) The impact of specific colloids on the growth and extra-cellular matrix (ECM) production of certain cells. (E) The additional functionalities that can be introduced into the synthetic tissue by selected colloids.

In this manuscript, the term "composite bioink" refers to an ink formulation including a cell population and colloidal particles in a polymer precursor solution. The term "colloid-free bioink" refers to a material containing cells in a polymer precursor solution, in the absence of colloids, and generally used as comparative systems to better highlight the effect of colloids. Finally, the term "biomaterial ink" and "composite biomaterial ink" are used to designate acellular materials (without and with colloid additives respectively) that have the ability to host cells after printing in accordance with the definition given in a recent perspective article. ${ }^{36}$ 


\section{PHYSICOCHEMICAL TAILORING OF BIOINKS BY EMBEDDED COLLOIDS}

Studies on the modification of bioinks ultimately aim at achieving the printing of well-defined and structurally stable constructs with encapsulated cells. In composite bioinks, embedded colloids bind with the macromolecular chains and create reversible physical crosslinks between neighboring polymer strands. These crosslinks arise either from electrostatic interactions between charged particles and oppositely charged polyelectrolytes ${ }^{15,37}$ or from hydrogen bonding between the surface of colloids and the hydroxyl and amine groups of the biopolymers composing the bioink (Figure 2-B). ${ }^{38-41}$ Thanks to the creation of these bonds, colloids influence the physicochemical properties of the ink in two distinct ways. First, they transform simple precursor polymer solutions (composite-free bioinks) into weakly crosslinked polymer networks with nonNewtonian behavior. These resulting materials display an increased viscosity as well as shearthinning and yielding behaviors which guarantee both the shape fidelity of the printed object and the survival of encapsulated cells. Second, after printing and immobilization in the form of permanently crosslinked hydrogels, embedded particles increase the stiffness of the printed structure and restrain its swelling so as to guarantee its shape stability. These distinctive impacts of colloids on the rheology of bioinks and on the mechanical characteristics of printed hydrogels are detailed separately in the following subsections.

\subsection{Colloids as rheology modifiers}

To illustrate the effect of colloids on the rheology of bioinks, two examples of composite systems are discussed and presented in Figure 3. On the one hand, a formulation containing methacrylated gelatin (GelMA) and cellulose nanofibers (CNF) (Figure 3-A). ${ }^{42}$ On the second hand, a solution

of agarose with silicate nanoplatelets (nSi) (Figure 3-E). ${ }^{43}$ In both cases, the polymer chains form 
weak physical crosslinks with the colloidal materials through hydrogen bonding. Rheological parameters recorded on other composite bioinks and their comparison with data obtained on colloid-free polymer solutions are presented in Table 1.

Viscosity and shear-thinning capability. Prior to the addition of colloids, polymer precursor solutions can either behave as Newtonian fluids, with viscosity independent from shear rates, as is the case for the pure GelMA solution represented by the black curve in Figure 3-B, or as low viscosity non-Newtonian fluids such as the pure agarose solution (white circles in Figure 3-F). These colloid-free solutions have a limited interest for bioprinting since their low viscosity will lead to a rapid spreading of the ink after printing and subsequent loss of resolution (as depicted in Figure 3-D(i)).

The introduction of colloids in these polymer suspensions leads to an increase in low-shear viscosity $\eta_{0}$ (Figure 3-B and F). This effect arises from the adsorption of polymer chains on the surface of the embedded particles and is consequently related to the concentration of colloidal materials (as seen in Figure 3-B and F). This colloid-induced increase in low-shear viscosity reduces the spreading of the composite bioink after dispensing. Hence, the post-printing shape fidelity is improved which enables the printing of taller structures (as displayed in Figure 3-D). ${ }^{42}$, ${ }^{44}$ However, care should be taken not to exceed a certain threshold since excessive viscosity may lead to nozzle clogging and induces high shear stress on the embedded cells during the printing process. ${ }^{13}$ As seen from Table 1, bioinks with low-shear viscosity ranging from 100 to $8000 \mathrm{~Pa}$ display adequate printability while ensuring cell-survival during dispensing. ${ }^{15,37,40,42,43,45-47}$ 
Table 1: Rheological parameters of different formulations of composite bioinks and comparison with rheological data obtained on precursor polymer solution prior to the addition of colloids.

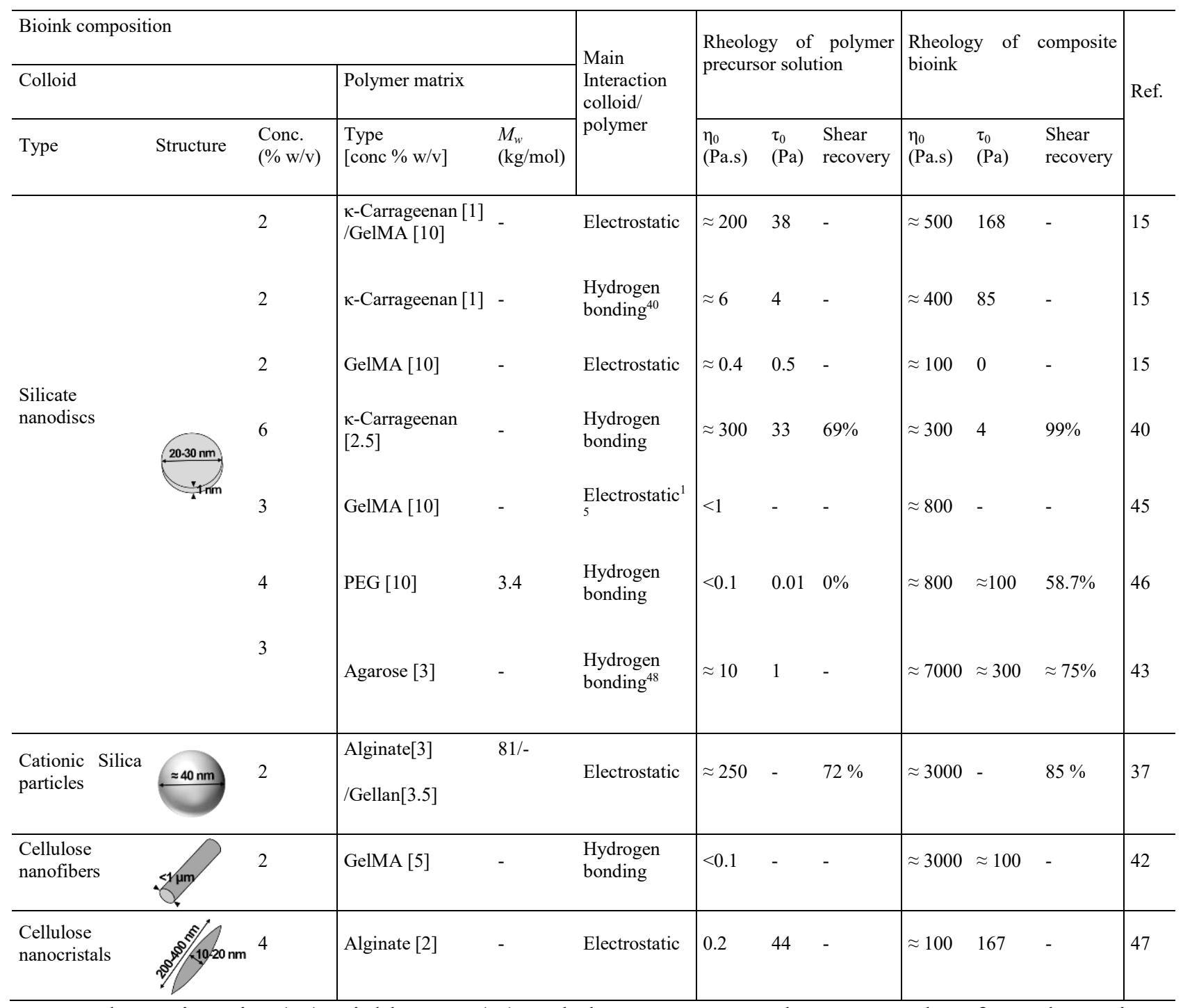

Low-shear viscosity $\left(\eta_{0}\right)$, yield stress $\left(\tau_{0}\right)$ and shear recovery values were taken from the main text or extracted from the displayed graphs of the articles cited in the reference column. The symbol (-) was used when data were not reported in the corresponding manuscript. 
Nevertheless, the physical crosslinks between colloid and polymers can easily dissociate under stress. This impart shear-thinning properties to the bioinks since strained macromolecules are able to regain their freedom and align along the flow direction when submitted to shear (as depicted in Figure 2-B). This is evidenced by a decrease in viscosity of composite bioinks with increasing shear rate as seen for both examples presented in Figure 3 (B and F). Such behavior is essential for bioprinting as it reduces the shear stress in the dispensing nozzle. Shear stress impacts both the integrity of encapsulated cells during printing and their ability to proliferate and differentiate after printing. ${ }^{13,49-51}$ It is important to note that the extent of shear-induced damages on cells depends on cell type and density as well as on the level and duration of shear stress, the latter being determined by the printing conditions. Hence, if the addition of colloids is a lever to tune the rheological properties of the bioink, it should come along with a careful selection of the printing parameters (printing speed, printing pressure, nozzle size and geometry) to allow for the dispensing of specific cell lines with high survival rates.

The increase of viscosity caused by the addition of colloids is observed for the vast majority of composite bioinks regardless of particle type, size and geometry (see Table 1). The composite systems presented in Table 1 were selected because their rheology were thoroughly characterized, but many other colloid types (calcium phosphate bioceramics, bioactive glass particles and strontium carbonate rods) lead to a similar increase in bioink viscosity. ${ }^{50,52-54}$ This underlines the versatility of this approach which can be transpose to many hydrophilic colloid species able to create weak interactions with biomacromolecules. 

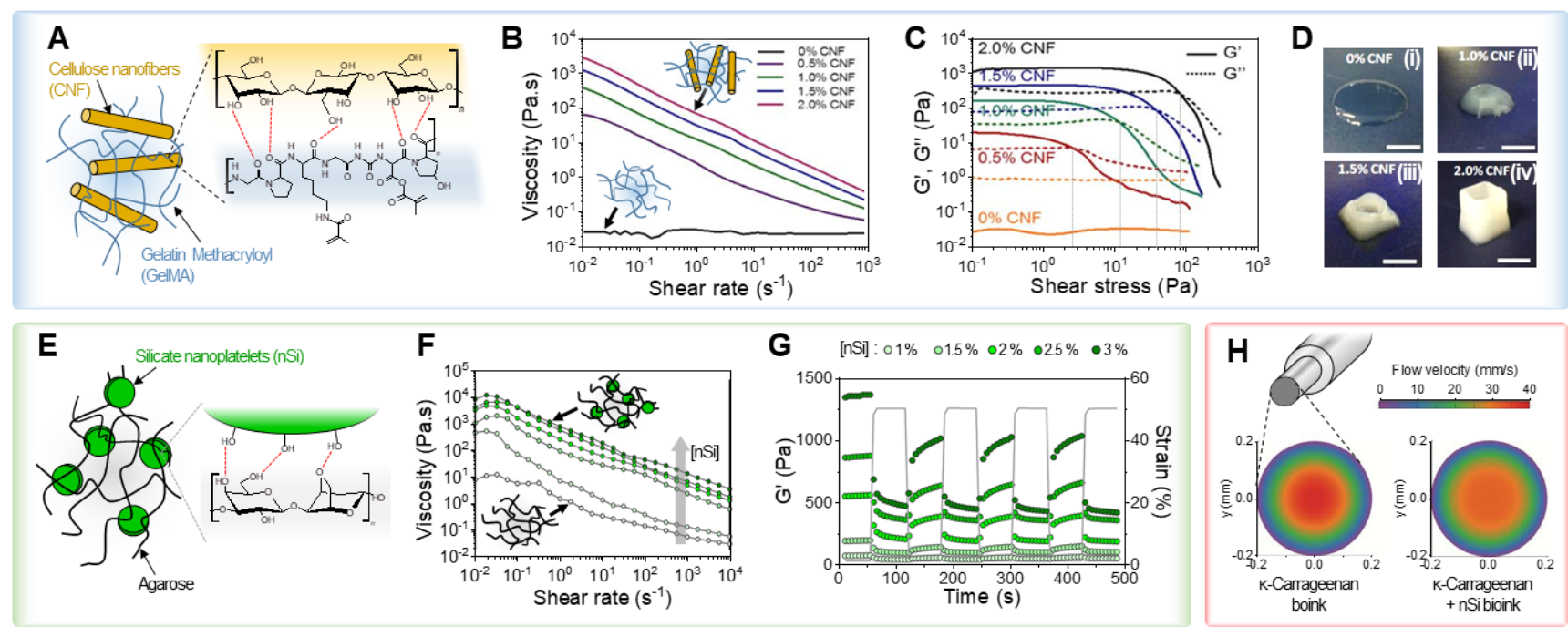

Figure 3 : Rheological modifications of bioinks by colloids. (A) Schematic representation of the interactions in a composite bioink containing cellulose nanofibers (CNFs) and methacrylated gelatin (GelMA). (B) Viscosity profile of GelMA-based bioinks with increasing CNF concentration. (C) Graph displaying the increase of yield-stress value in GelMA bioinks with increasing CNF concentrations. (D) Shape stability of hollow cube structures printed with GelMA bioinks containing increasing amounts of CNF (scale bar: $1 \mathrm{~cm}$ ). The inserts $\mathrm{B}, \mathrm{C}$ and $\mathrm{D}$ are reproduced from ref ${ }^{42}$ Copyright 2017, with permission from the author. (E) Schematic representation of the interactions in a composite bioink containing silicate nanoplatelets (nSi) and agarose. (F) Viscosity profile of agarose-based bioinks with increasing $\mathrm{nSi}$ concentration. (G) Shear recovery experiments on agarose-based bioinks with increasing $\mathrm{nSi}$ concentration. Inserts $\mathrm{F}$ and $\mathrm{G}$ are reproduced from ref ${ }^{43}$. Copyright 2019, with permission from the American Chemical Society. $(\mathrm{H})$ Simulated velocity profiles of a $\kappa$-carrageenan bioink and a $\kappa$-carrageenan $/ \mathrm{nSi}$ composite bioink as they pass through the extruder tip in the same printing conditions. Reproduced from ref ${ }^{15}$. Copyright 2018, with permission from the American Chemical Society. 
Yied stress. Embedded colloids also influence the yield stress $\left(\tau_{0}\right)$ of bioinks which corresponds to the mimimum stress necessary to initiate the flow. In other words, when submitted to a shear stress lower than its yield stress, the bioink behaves as a viscoelastic solid. If many studies focus on the viscosity and shear-thinning behavior of bioinks to tune their printability, recent reports have shown the key influence of yield stress on the shape fidelity of bioinks. ${ }^{14,15}$ As a matter of fact, bioinks combining shear thinning and yielding behavior, i.e. following the Hershel-Bulkley law, ${ }^{11}$ exhibit a flow profile referred to as "plug flow". ${ }^{11,15,16,55}$ In this case, only the edge of the ink in contact with the nozzle walls experience shear thinning. This creates a lubricating layer that enables the central part of the ink to be extruded relatively undeformed through the nozzle. Such flow profile leads to the printing of well-defined viscoelastic filaments yielding printed construct with enhanced shape fidelity. Experimentally, $\tau_{0}$ can be obtained by following the viscosity drop with increasing shear stress (As represented in Figure 1-(ii)). ${ }^{14}$ However, it is often approximated to the LVER (limit of linear viscoelastic region) from oscillatory experiments which corresponds to the stress value at which the storage modulus (G') and loss modulus (G') cross (as depicted in Figure 1-(iii)). ${ }^{40,42,43}$

In the case of the GelMA/CNF composite systems presented in Figure 3, the pure GelMA solution behaves as a Newtonian fluid and, as such, do not exhibit yield stress (orange curves in Figure 3-C). The addition of CNF in this solution leads to weakly crosslinked composite materials that display a yield stress which value increases with increasing CNF concentrations. ${ }^{42}$ This modification of yield stress values by the addition of colloids was reported for many composite bioinks (Table 1). In addition, by inducing a yielding behavior in bioinks, embedded colloids modify the flow profile of the material. ${ }^{11,15,55}$ For example, $\mathrm{nSi}$ included in $\kappa$-Carrageenan solutions reduce the velocity gradient in the nozzle and lead to the creation of a plug flow as seen 
in Figure $3-\mathrm{H}^{15}$ As mentioned above, this flow profile improves the shape fidelity of printed constructs but it also shields encapsulated cells from shear. In fact, as explained previously, cells are sensitive to shear stress which is generated by the velocity gradient within the dispensing nozzle.$^{56}$ Hence, by reducing the velocity gradient and inducing plug flow, colloids protect the cells contained in the central part of the bioink from excessive shear stress.

Interestingly, in some specific cases, colloid materials can also be employed to decrease the yield stress of bioinks so as to simplify their extrusion. In a recent work, nSi were incorporated in a bioink containing a relatively large concentration of $\kappa$-Carrageenan $(2.5 \% \mathrm{w} / \mathrm{v})$ and were found to decrease its yield stress values, arguably by disrupting the strong polymer-polymer interactions. $^{40}$

Shear recovery. As explained previously, bioinks displaying shear-thinning and yielding behaviors recover their solid-like behavior after printing. However, in order to ensure a satisfactory print resolution, the bioink should recover a large fraction of its original modulus in a short time. The extent and kinetics of shear recovery can be probed by submitting the bioink to successive steps of high and low strain and measuring the time necessary for its modulus to reach its solidlike equilibrium value (see model graph in Figure 1-(iv) and experimental data in Figure 3-G). Examples of composite bioinks for which this characterization was performed displayed relatively high percentages of modulus recovery ranging from $50 \%$ to up to $99 \%$ (see Table 1 ). In the case of the agarose/nSi bioinks presented in Figure 3, the formulation containing the largest $\mathrm{nSi}$ concentration $(3 \% \mathrm{w} / \mathrm{v})$ recovered about $75 \%$ of its original modulus after the first high strain step and about $100 \%$ after the following steps (Figure 3-G). The recovery times of tested composite bioinks were found to be relatively long, in the order of tenths of seconds. ${ }^{37,43,46}$ For instance, the agarose/nSi bioinks recovery time was around 50 seconds (Figure 3-G). This duration may be 
considered as too long to ensure the print resolution in the case of low-viscosity colloid-free bioinks. However, in most cases of composite bioinks, although the time necessary to attain the maximum modulus recovery is long, the systems very rapidly reached high modulus values $(\geq 500$ $\mathrm{Pa}$ ) that were found sufficient to ensure the structural integrity and resolution of the printed construct. $^{37,43,46}$

Influence of polymer chain length and particle size. As is seen in Table 1, very few studies focus on the impact of polymer chain length $(\mathrm{Mw})$ and particle size on the rheology of composite bioinks. This is rather surprising since these parameters have an important effect on colloid/polymer interaction and, consequently, on the rheology of composite bioinks. For instance, when colloids are too large compared to the persistence lengths of polymers, their effect on the bioink rheology is dramatically reduced as colloidal particles may not be bridged by polymer strands but rather coated by them. ${ }^{37}$ Conversely, using increasingly long polymer chains was found to decrease the storage modulus of polyethylene oxide/nSi composite materials. ${ }^{57}$ This can be correlated to the reported tendency of long polymer chains to induce aggregation of small colloids. ${ }^{37,58}$ Such aggregation is to be avoided as it both decreases the interacting surface area of the colloidal material and also promote clogging in the printing nozzle. ${ }^{37,59}$ This underlines the need to take into account the structural parameters of the colloid and polymer species in the optimization of composite boinks.

\subsection{Colloids for printed hydrogel reinforcement}

After printing, the bioink must be permanently crosslinked to ensure the long-term stability of the cell-laden printed object. This is either done by UV irradiation if the polymeric components of the bioink display photopolymerizable groups, or by incubation in a solution that contains physical or chemical crosslinker molecules. In the case of composite bioinks, colloids embedded in the 
permanently crosslinked hydrogels, by maintaining their role of additional crosslinkers, modify the structure of the hydrogel network and thus influence its mechanical properties and its ability to swell. Table 2 presents a list of the mechanical characteristics and swelling properties of printed composite hydrogels compared to data obtained on colloid-free systems. 
Table 2: Mechanical and swelling characteristics of composite hydrogels printed with composite bioinks and comparison with data obtained on corresponding colloid-free hydrogels.

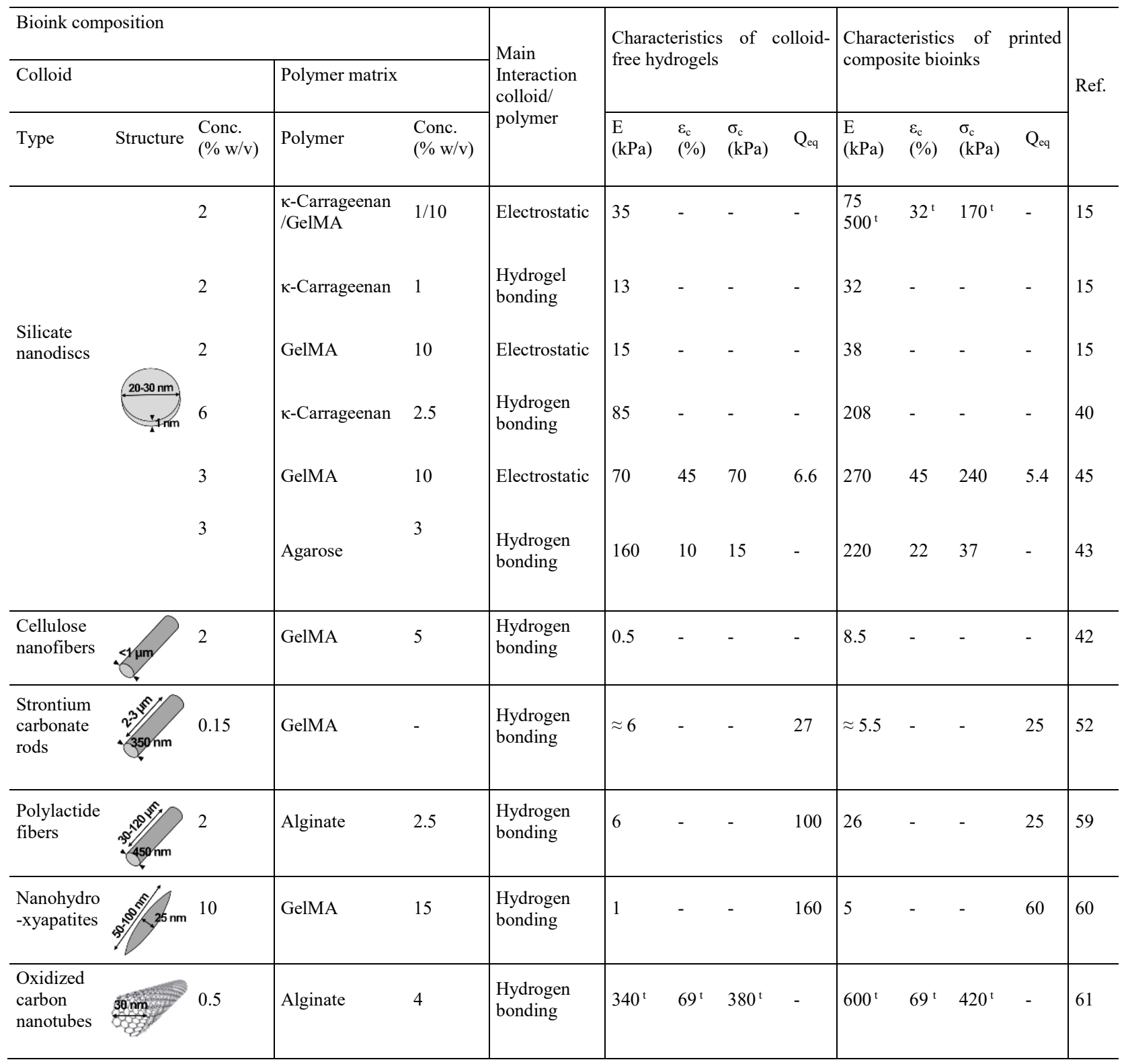

Elastic modulus $(E)$, fracture strain $\left(\varepsilon_{\mathrm{c}}\right)$, fracture stress $\left(\sigma_{\mathrm{c}}\right)$ and equilibrium swelling $\left(\mathrm{Q}_{\mathrm{eq}}\right)$ values were taken from the main text or extracted from the displayed graphs of the articles cited in the reference column. The symbol $\left({ }^{t}\right)$ was used for data obtained by tensile test, all other data were measured by compressive test. The symbol (-) was used when data were not reported in the corresponding manuscript. 
Elastic modulus and fracture stress $\&$ strain. After printing, embedded colloids play the role of fillers and strengthen the mechanical properties of printed hydrogels. More precisely, when the printed composite material is deformed, the strained polymer chains adsorbed on colloids can detach from the particle surface and relax the tension thereby dissipating viscoelastic energy without breaking the permanently crosslinked hydrogel network (as depicted in Figure 2-C). ${ }^{22}$ In addition, as the colloid/polymer interactions are weak, there is a constant traffic of monomers between the adsorbed and desorbed state. Consequently, once a strand detaches a neighboring strand can adsorb at its place. This exchange process contributes to the strengthening of the material. ${ }^{62,63}$ Thanks to this reinforcement mechanism, colloids have been shown to increase the elastic modulus (E) of printed hydrogels as evaluated by tensile or compressive tests (see Table 2). For instance, in the case of the agarose/nSi system described earlier (see Figure 3-E), the presence of $3 \% \mathrm{w} / \mathrm{v}$ of $\mathrm{nSi}$ in the printed hydrogel led to an increase of compressive modulus from $160 \mathrm{kPa}$ (for the colloid-free hydrogel) to $220 \mathrm{kPa}$. In a similar fashion, the fracture stress $\left(\sigma_{\mathrm{c}}\right)$ and fracture strain $\left(\varepsilon_{c}\right)$ of this system were both significantly improved by the presence of $\mathrm{nSi}^{43}{ }^{43} \mathrm{As}$ seen in Table 2, the elastic modulus and fracture stress of printed hydrogels are almost systematically enhanced by the presence of colloids apart from one example for which the colloid concentration was very low. ${ }^{52}$ The effect of embedded particles on the fracture strain is less obvious but does not lead to a significant decrease of this parameter.

Interestingly, only a small amount of nanoparticles (in the range of $1 \% \mathrm{w} / \mathrm{v}$ ) is necessary to induce dramatic changes in the mechanical properties of the gel. ${ }^{11,40,61}$ This effect of colloids on mechanical properties depends on the concentration as in most cases, values of elastic moduli increase with increasing colloid concentration..$^{40,43,45,61,64}$ Nevertheless, in some cases, the addition of colloids above a certain quantity was found to have no additional effect on elastic 
moduli of printed composite hydrogels. ${ }^{43}$, 52 This underlines the necessity to adjust the concentration of colloidal materials especially since excessive amounts of colloids can decrease the moduli of composite polymer systems. ${ }^{65,66}$ This detrimental effect is generally attributed to the aggregation of colloids which both decrease their interacting surface area and introduce brittleness in the material.

Swelling and shape stability. The long-term shape stability of the printed biomaterial is also a key factor conditioning its maturation and implantation. After printing, hydrogels are generally stored in aqueous cell culture media to promote cell growth and proliferation. Being hydrophilic polymer networks, hydrogels immersed in these solutions have the tendency to swell, a process during which they progressively absorb the surrounding solution until reaching their equilibrium swelling $\left(\mathrm{Q}_{\mathrm{eq}}\right)$ (as schematically represented in Figure 1-(v)). This phenomenon induces a change in the size of the printed object and can damage surrounding tissue in case of a direct implantation. ${ }^{67}$ As seen in Table 2 , the presence of colloids in printed hydrogel was found to lower their equilibrium swelling. In fact, by creating additional crosslinks the embedded particles reduce the network mesh size which is directly related to the swelling capacity of the gel. This ability of colloids to limit the extent of water uptake and restrain the expansion of the hydrogel network is interesting with regards to ensuring the shape retention of the printed object.

Comparison with other reinforcement strategies. Other approaches have been reported to strengthen the mechanical properties of printed hydrogels such as the chemical functionalization of polymer chains, ${ }^{68}$ the integration of an interpenetrating network ${ }^{15}$ and the co-printing of bioinks with thermoplastic scaffolds. ${ }^{69}$ A recent review by Gaharwar and coworkers nicely summarizes these different methods. ${ }^{11}$ The main interest of colloid-based reinforcement lies in the simplicity and versatily of this strategy. Firstly, the addition of nanoparticles does not require chemical 
modification of the polymers contained in the ink. And secondly, given the chemistry of biomacromolecules employed for bioprinting - displaying hydroxyl, amine and carboxylic groups - a large variety of hydrophilic colloidal particles are able to interact with these molecules through hydrogen bonding and/or electrostatic interactions. The main issue of this approach resides in the potential toxicity of colloids which is further discussed in the section 4 of this manuscript.

\section{COLLOID-GUIDED TISSUE FORMATION}

Colloidal particles embedded in bioinks have been also found to greatly influence the behavior of printed cells. In fact, colloids may guide the cell fate by interacting with the cells through adhesion mechanisms, mechanotransduction processes and biochemical pathways.

Firstly, it is known that certain nanomaterials such as silica nanoparticles, silicate-based nanoparticles, carbon nanotubes or gold nanoparticles provide binding sites for cellular adhesion. ${ }^{26,70-72}$ In bioinks, these adhesion sites could be combined with the RGD (Arg-Gly-Asp) cell binding sequences naturally present ${ }^{73}$ or chemically grafted $^{74}$ on the polymer matrix. Promoting cellular adhesion is essential as it plays a key role in defining cell shape and organization. ${ }^{75}$

Secondly, the mechanical strengthening of hydrogels induced by embedded colloids (as discussed in section 2.2) may also impact the cell fate. Cells react to mechanical variations in their surrounding through mechanotransduction processes. Hence, by monitoring the matrix stiffness, it is possible to guide the cell differentiation. ${ }^{76-79}$ For instance, seminal work showed that when mesenchymal stems cells (MSCs) are grown on the surface of a soft matrix $(\mathrm{E} \leq 1 \mathrm{kPa})$ that mimic brain tissues, they differentiate into neural cells. Conversely, using a stiffer $(\mathrm{E} \approx 10 \mathrm{kPa})$ or rigid (E $\geq 20 \mathrm{kPa}$ ) matrix will lead to myogenic (muscle tissue) and osteogenic (bone tissue) 
differentiation, respectively. ${ }^{77}$ Similar results have been obtained in 3D culture of cells in alginatebased hydrogels in which MSCs underwent adipogenic differentiation in relatively soft hydrogels $(\mathrm{E}=9 \mathrm{kPa})$ and osteogenic differentiation in stiffer gels $(\mathrm{E}=17 \mathrm{kPa})$. Hence, colloidal particles included in bioinks, by modifying the elastic modulus of printed hydrogels, could provide an interesting mean to control the differentiation of encapsulated cells.

Moreover, the porosity of the polymer matrix and its viscoelastic properties also affect the tissue formation as it impacts the cell migration. ${ }^{76,80}$ Interestingly, both these parameters (porosity and viscoelastic response) can be controlled by including colloids in the bioink formulation. On the one hand, as mentioned in section 2.2 , the additional crosslinks formed by colloids along the polymer matrix reduce the mesh size of the hydrogel network and allows for controlling the gel porosity and swelling capacity. ${ }^{66}$ However, it is important to note that lowering the mesh size can negatively impact the differentiation of stem cells as well as the nutrient flux throughout the gel. ${ }^{81}$, ${ }^{82}$ On the other hand, polymer strands crosslinked by nanoparticles exhibit viscoelastic properties ${ }^{83}$ since adsorbed polymer chains can easily desorb, reorganize and dissipate energy under stress (as shown in Figure 2-C). Hence, printed composite hydrogels could respond to local cellular stresses and allow cell spreading by structural rearrangement.

Finally, the chemical composition of the embedded colloids, their degradation rate, their degradation products as well as their specific functionalities (electroactivity, drug release capability, etc.) has an important effect on cell differentiation and can be used to guide the tissue formation toward a specific tissue type. A more detailed description of the distinct properties of embedded colloids and their role in the maturation of different printed tissues is exposed in this section. 
Table 3 presents a list of the composite bioinks for extrusion printing classified according to the targeted tissue type. It can be noticed that many references cited in Table 3 do not appear in Table 1 and 2. In these studies, the focus was placed on biological considerations (growth and differentiation of cells, tissue formation, etc.) rather than on the rheological and mechanical characterization of the composite bioink.

Table 3: Summary of the different composite systems used in the formulation of bioinks for extrusion bioprinting of specific targeted tissues.

\begin{tabular}{|c|c|c|c|c|}
\hline Tissue Type & & Colloid type & Polymer matrix & Ref. \\
\hline \multirow{12}{*}{ Bone tissues } & & \multirow{5}{*}{ Hydroxyapatite particles } & alginate/polyvinyl alcohol & 84 \\
\hline & & & $\begin{array}{l}\text { methacrylated gelatin/ methacrylated } \\
\text { hyaluronic acid }\end{array}$ & 73 \\
\hline & & & methacrylated gelatin & 53 \\
\hline & & & chitosan & 85 \\
\hline & & & alginate/gelatin & 86 \\
\hline & & $\beta$-tricalcium phosphate crystals & collagen & 87 \\
\hline & & \multirow{2}{*}{ Bioactive glass } & alginate/gelatin & $54,88,89$ \\
\hline & & & alginate dialdehyde & 89 \\
\hline & & \multirow{2}{*}{ Clay nanopletelets } & methacrylated gelatin & $90-92$ \\
\hline & & & gellan & 92 \\
\hline & & Nano-graphene oxide & alginate & 93 \\
\hline & & Strontium particles & methacrylated gelatin & 52 \\
\hline \multirow{9}{*}{ Cartilage tissues } & & \multirow{3}{*}{ Nanocellulose } & alginate & $94-96$ \\
\hline & & & alginate sulfate & 50 \\
\hline & & & hyaluronic acid & 97 \\
\hline & & \multirow[t]{2}{*}{$\beta$-tricalcium phosphate crystals } & methacrylated gelatin/aglinate & 98,99 \\
\hline & & & $\begin{array}{l}\text { methacrylated gelatin/ methacrylated } \\
\text { hyaluronic acid/ methacrylated } \\
\text { chitosan }\end{array}$ & 99 \\
\hline & & Hydroxyapatite particles & alginate/gelatin & 100 \\
\hline & & Cartilage fragments & alginate/ gellan & 101 \\
\hline & & PLGA nanoparticles & methacrylated hyaluronic acid & 102 \\
\hline & & Silica nanoparticles & alginate/ gellan & 37 \\
\hline \multirow{4}{*}{$\begin{array}{l}\text { Electroactive } \\
\text { tissues }\end{array}$} & Muscle & PEDOT:PSS nanoparticles & methacrylated gelatin & 103 \\
\hline & \multirow{2}{*}{ Cardiac } & Carbon nanotubes & methacrylated collagen & 104 \\
\hline & & Gold nanoparticles & methacrylated gelatin & 105 \\
\hline & Neural & Graphene & polyurethane & 106 \\
\hline Vascular tissues & & Carbon nanotubes & alginate & 61 \\
\hline Liver tissues & & Nanocellulose & alginate & 47 \\
\hline Adipose tissues & & Nanocellulose & alginate & 107 \\
\hline
\end{tabular}




\subsection{Bone printing}

Bone grafting is the most common transplantation surgery worldwide with more than 2 million procedures every year. ${ }^{108}$ In that context, bioprinting of bone tissues has been a very active field of research due to its potential for the rapid fabrication of geometry-specific biomimetic implants. Accordingly, a growing attention has been devoted to the use of colloids in bioink for bone printing. This is initially motivated by the necessity of increasing the stiffness of the gel matrix above a certain threshold $(\mathrm{E}>20 \mathrm{kPa})$ in order to promote osteogenesis as mentioned above.

But beyond this mechanical contribution, which can be achieved with various colloidal particles, specific colloid types have the ability to influence the kinetics and the extent of bone formation (osteogenesis). Over the past few years a great variety of colloidal materials have been introduced into bioinks for bone printing including calcium phosphate bioceramics, ${ }^{53,73,84-87}$ silicate-based particles,${ }^{54,88-92}$ and also more recently graphene oxide colloids ${ }^{93}$ and strontium carbonate nanoparticles. ${ }^{52}$

Calcium phosphate bioceramics. The most commonly used nanomaterials for bone bioprinting are synthetic calcium phosphate bioceramics such as hydroxyapatite particles (HAp) $\left(\mathrm{Ca}_{10}\left(\mathrm{PO}_{4}\right)_{6}(\mathrm{OH})_{2}\right)^{53,73,84-86,109,110}$ or $\beta$-tricalcium phosphate crystals $(\beta-\mathrm{TCP})\left(\mathrm{Ca}_{3}\left(\mathrm{PO}_{4}\right)_{2}\right) .{ }^{87,}{ }^{109}$, 111, 112 Their interest lies in their chemical composition which is very similar to the bone mineral and their osteogenic effect on osteoprogenitor cells and stem cells. ${ }^{113,114}$ The exact mechanism by which calcium phosphate particles influence the fate of cells is not fully understood but is believed to involve DNA methylation, ${ }^{115}$ mechanostransdution ${ }^{14-116}$ and the release of high level of calcium and phosphate ions. ${ }^{114,116}$ In addition, the osteogenic effect of these particles was found to depend on their size and structural properties. ${ }^{117}$ For their inclusion in bioinks, they are used in the form of micron- or nano-sized crystals suspended in a solution ${ }^{85}$ or in the form of powder. ${ }^{73}$ 
A

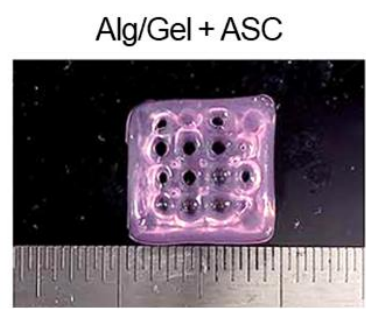

$\mathrm{Alg} / \mathrm{Gel}+\mathrm{ASC}+\mathrm{HAp}$
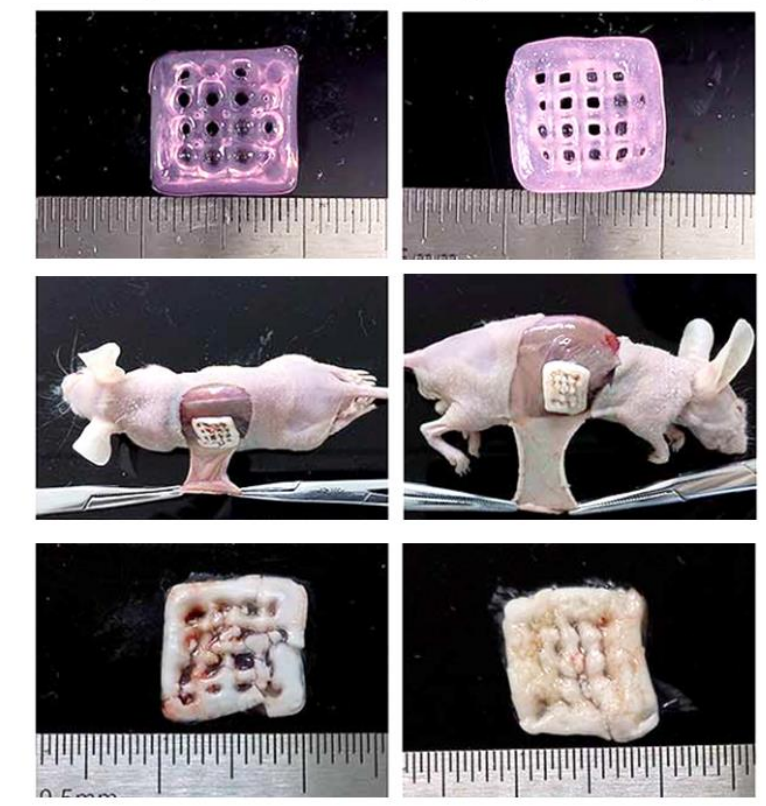

B

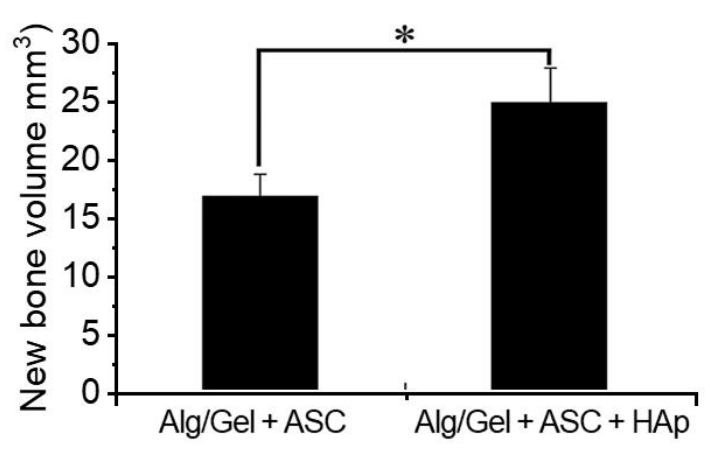

Figure 4: Bone printing: (A) Morphology of printed alginate/gelatin/adipose stem cells (hASCs) bioinks with and without nano-hydroxyapatite, before and after 8 weeks of subcutaneous implantation in nude mice. (B) Radiological assessment of bone formation in both bioinks after implantation. Reproduced with permission of the Royal Society of Chemistry from ref ${ }^{86}$, Copyright 2016, permission conveyed through Copyright Clerance Center, Inc.

In bioprinted constructs, HAp of different size $(200 \mathrm{~nm}-100 \mu \mathrm{m})$ were reported to enhance osteogenic differentiation of adipose stem cells $(\mathrm{ASC})^{73,86}$ and preosteoblasts. ${ }^{85}$ Their presence was also found to accelerate the production of bone minerals by differentiated cells in vitro ${ }^{73,85}$, 
${ }^{110}$ as well as in vivo in mice (Figure 4-A and B). ${ }^{86}$ Nanosized HAp (50-100 nm) were also used in bioinks containing breast cancer cells $(\mathrm{BrCa})$ and MSCs for the bioprinting of tumor models to study post metastatic breast cancer progression in bone tissues. ${ }^{60}$

Similarly, the inclusion of $\beta$-TCP nanocrystals in collagen-based bioprinted scaffold was shown to improve the proliferation and the osteogenic activities of preosteoblats and ASCs. ${ }^{87}$ However, above a certain concentration ( $>20 \mathrm{wt} . \%$ ), $\beta$-TCPs particles had a negative impact on both printability and post-printing cell viability. ${ }^{87}$ This effect can be attributed to the high viscosity of concentrated bioinks which, by causing a high shear stress in the printing nozzle, severely damaged the cell during the extrusion process. Other studies, dealing with composite biomaterial inks (i.e. acellular composite inks which were seeded with cells after printing), confirmed an enhancement of cell proliferation, osteogenic activities and osteogenic gene expression in the presence of $\beta$ TCP. ${ }^{111,112}$

The choice between HAp and $\beta$-TCP as additives for bone printing can be guided by a recent work comparing the influence of both HAp and $\beta$-TCP on bone regeneration in-vivo. Both materials with similar structure and porosities were included in poly(lactic-co-glycolic acid) (PLGA) and their performance for the regeneration of rabbits' calvarial bone was tested. ${ }^{118}$ This study, which did not involve bioprinting, led to the observation that HAp loaded PLGA-based biomaterials exhibit higher stiffness and enhanced cell proliferation at an early stage. However, HAp showed no sign of degradation in vivo. ${ }^{118,119}$ Conversely, $\beta$-TCP was shown to be slowly absorbed thereby making room for new bone growth. Owing to this biodegradability, $\beta$-TCP may be considered a superior bioceramic for bone tissue repair. In addition, certain nanosized HAp have been reported to be cytotoxic to osteoblasts. For instance, hydroxyapatite nanorods (length $80 \mathrm{~nm}$ and diameter $20 \mathrm{~nm}$ ) were found to induce apoptosis in osteoblastic cells through oxidative 
stress-induced lysosomal and mithochondrial pathways. ${ }^{120}$ In contrast, another study reported that hydroxyapatite nanospheres (diameter $20 \mathrm{~nm}$ ) promote the growth and inhibit apoptosis of osteoblastic cells. ${ }^{121}$ These somehow contradictory results underline the difficulty of properly assessing the cytoxicity of colloid materials which is a crucial challenge for the development of composite bioinks (as discussed in the section 4 of this manuscript).

Silicate-based colloids. There are two main types of silicate-based materials used as additives in bioinks for bone printing : bioactive glass particles ${ }^{54,88,89}$ and clay nanoplatelets..$^{90-92}$

Bioactive glasses $\left(\mathrm{Na}_{2} \mathrm{O}-\mathrm{CaO}-\mathrm{SiO}_{2}-\mathrm{P}_{2} \mathrm{O}_{5}\right)$ are glass-ceramic nanomaterials consisting of various proportions of silica $\left(\mathrm{SiO}_{2}\right)$, calcium oxide $(\mathrm{CaO})$, sodium oxide $\left(\mathrm{Na}_{2} \mathrm{O}\right)$ and phosphorus pentoxyde $\left(\mathrm{P}_{2} \mathrm{O}_{5}\right)$. These nanoparticles form a strong chemical bond to bone mineral and their dissolution products ( $\mathrm{Si}, \mathrm{Ca}, \mathrm{P}$ and $\mathrm{Na}$ ions) stimulates osteoprogenitor cells at the genetic level to promote rapid bone formation. ${ }^{122,}{ }^{123}$ In printed composite bioinks, bioactive glass was reported to enhance the osteogenic activities of osteoblast-like cells (MG-63 and SaOS-2 cells) as well as bone marrow-derived mesenchymal stem cells (BMSCs) and led to rapid mineralization of the bioprinted construct. ${ }^{54,88,89}$ However, it is important to note that the increase in viscosity due to the presence of bioactive glass particles yielded, in some cases, a lower post-printing viability of SaOS-2 cells. ${ }^{54}$ Surprisingly, this effect was not observed with BMSCs which underlines the cellspecific sensitivity to shear stress. A parameter that must be taken into account in the design of composite bioinks.

Clay nanoplatelets, most commonly made of laponite $\left.\left(\mathrm{Na}_{0.7}^{+}\left[\left(\mathrm{Mg}_{5.5} \mathrm{Li}_{0.3}\right) \mathrm{Si}_{8} \mathrm{O}_{20}(\mathrm{OH})_{4}\right]^{-}{ }_{0.7}\right)\right)$, are cytocompatible nanomaterials that dissociate into nontoxic products $\left(\mathrm{Na}^{+}, \mathrm{Mg}^{2+}, \mathrm{Si}(\mathrm{OH})_{4}, \mathrm{Li}^{+}\right)$ having the ability to trigger specific cellular responses toward osteogenesis induction. ${ }^{124}$ They are typically used in the form of disc shape nanoparticles $(1 \mathrm{~nm}$ in thickness and $25-100 \mathrm{~nm}$ in 
diameter) which possess a positively charged rim and a negatively charged surface. ${ }^{91,124}$ Thanks to this peculiar structure, clay nanoplatelets can interact with many biomacromolecules (in particular polyelectrolytes of different charges) which grants them with a high potential as rheology modifiers for bioinks.

When used as additives in bioink formulations, nanoplatelets induced concentration dependent osteogenic differentiation and enhanced mineralized nodule formation. ${ }^{90-92}$ Building on these properties of nanoclay, Byambaa et al, reported on the co-bioprinting of a nanoclay-loaded hydrogel inducing osteogenesis and an hydrogel containing endothelial cells (HUVEC) supporting vasculogenesis. ${ }^{90}$ The so-obtained tissue construct, judiciously combining mechanical response, degradability and bioactivity of the printed materials allowed for the formation of perfusable bonelike tissues. This represents an important progress as the vascularization of printed tissues is key to their long term viability.

Nano-graphene oxide. Nanographene oxide ( $\mathrm{nGO}$ ) is a derivative of graphene consisting of nanosized $(<100 \mathrm{~nm})$ planar carbon structure with high density of oxygen functional groups. ${ }^{125}$ Owing to these oxygen groups, these graphene derivatives can interact with hydrophilic polymer chains by hydrogen bonding. It is also cytocompatible and exhibits electrical conductivity which makes it interesting for the bioprinting of electroactive tissues (see section 3.3). ${ }^{126}$ In the case of bone printing, nGO introduced in bioinks were found to ensure a better survival rates of MSCs in oxidative stress environment compared to colloid-free bioinks. ${ }^{93}$ This protective role of nGO can be tentatively attributed to their antioxidant property that can neutralize reactive oxygen species (ROS) known to induce apoptosis of osteoblasts and osteocytes. ${ }^{127}$ Besides, the presence of nGO in the printed construct led to enhanced osteogenic differentiation. ${ }^{93}$ This effect may come from the fact that graphene-based nanomaterials can act as adsorbing platforms for osteogenic inducers 
contained in the osteogenic culture medium. ${ }^{128}$ In this way, nGO contribute to locally increase the concentration of these chemical species and magnify their effect.

Strontium based particles. Strontium has the ability to enhance bone formation, reduce bone resorption and integrate with bone hydroxyapatite due to its chemical similarity with calcium. ${ }^{52}$, ${ }^{129}$ Hence, strontium is believed to interact with calcium sensing receptors of osteoprogenitor cells leading to an enhanced proliferation, osteogenic differentiation and bone mineral formation. As such it has been used as doping materials for HAp to enhance their osteogenic properties both in classical tissue engineering ${ }^{129}$ and in bioprinting. ${ }^{89}$ In a recent work, strontium carbonate $\left(\mathrm{SrCO}_{3}\right)$ nanoparticles $(\approx 15 \mathrm{~nm})$ were also directly used in bioink for bone printing. In this context, it was reported to increase the viscosity as well as to enhance MSCs viability and osteogenic differentiation leading to rapid mineralized nodule formation. ${ }^{52}$

\subsection{Cartilage printing}

In recent years, growing attention has been devoted to the bioprinting of cartilage. Printed cartilage implants may be useful for the treatment of articular cartilage lesions that can evolve in secondary arthritis. ${ }^{97}$ Furthermore, such synthetic tissues can be used in the reconstructive surgery of cartilage damages or malformations (such as microtia). ${ }^{96}$ In this context, colloids such as nanocellulose, calcium phosphate bioceramics or poly(lactic-co-glycolic acid) (PLGA) nanoparticles have been added to bioinks to improve their printability and promote the production of cartilage tissues (chondrogenesis) in printed constructs.

Nanocellulose. Nanocellulose, extracted from the biosynthesis of plants or bacteria, is an emerging class of naturally derived nanomaterial ${ }^{94}$ which can be classified into three groups: (1) biomass-derived cellulose nanocrystals (CNC). (2) bio-mass-derived cellulose nanofibrils (CNF). (3) bacterial nanocellulose (BNC). 
Recent experimental works on nanocellulose loaded bioinks for cartilage printing have shown the potential of all types of nanocellulose $(\mathrm{CNC}, \mathrm{CNF}, \mathrm{BNC})$ to enhance the production of cartilage tissues ${ }^{50,94-97}$ Before printing, nanocellulose was found to promote chondrocyte (constitutive cells of cartilage tissues) spreading and proliferation within the bioink. ${ }^{50}$ Post-printing, nanocellulose guaranteed high cell viability and provided a biologically relevant environment that supported the redifferentiation of human chondrocytes, the maintenance of their rounded phenotype as well as the neosynthesis of cartilage specific extracellular matrix components (such as collagen II). ${ }^{94,96}$ Furthermore, induced pluripotent stem cells (iPSCs) included in printed constructs and co-cultured with irradiated mature chondrocytes (iChons) were reported to lose their pluripotency in the presence of cellulosic particles after 5 weeks in chondrogenic culture medium. ${ }^{97}$ In this period, they also produced cartilaginous tissues containing collagen II. ${ }^{97}$

Nevertheless, in one case, the viability and growth of chondrocytes printed in nanocellulose bioinks was found to be dependent on the diameter of the printing nozzle. ${ }^{50}$ While the use of small nozzles $(<250 \mu \mathrm{m})$ hindered cell growth, bioprinting through larger nozzles - thereby inducing a lower shear stress - led to a rapid proliferation of the cells within the material. This underlines the key role played by the printing process and show the importance of nonprinted control materials to fully assess the effect of shear stress on printed cells.

Calcium phosphate bioceramics. In addition to their application for bone tissue regeneration (see section 3.1), calcium phosphate bioceramics were also experimentally used for cartilage printing. ${ }^{98-101}$ In particular, $\beta$-TCP was included in bioinks in order to print synthetic tissues that mimic the calcified cartilage of osteochondral domains. ${ }^{98,99}$ The osteochondral (OC) tissue, found in human articulations, is composed of a thin translucent cartilage layer (hyaline cartilage) on an underlying subchondral bone. This combination provides an efficient bearing system for the 
movement of the limbs but is unable to regenerate in response to trauma or disease. ${ }^{98}$ Consequently, it is highly relevant to develop osteochondral tissue printing and in particular the fabrication of calcified cartilage ${ }^{98}$ which constitutes the intermediate layer between articular bone and the superficial cartilage layer.

To this aim, printed $\beta$-TCP-laden bioinks cultured in chondrogenic medium were found to foster differentiation of MSCs into chondrocytes and to promote their maturation into hypertrophic phenotypes that were characteristic of calcified cartilage. ${ }^{98,99}$ Furthermore, in an attempt to mimic the gradient composition of the osteochondral transition, Idazsek and corworkers fabricated a biomaterial displaying a vertical gradient in $\beta$-TCP concentration thanks to the use of a microfluidic mixing unit incorporated into an extrusion bioprinter (Figure 5-A and B) ${ }^{98}$ This heterogeneous composition caused a differentiated tissue formation throughout the material which finally led to an original bioconstruct ressembling the osteochondral zone. Using a similar strategy, Luo and coworkers developed a 3D printed bi-partite scaffold for repair of osteochondral defects in which the bony part was populated with HAp. ${ }^{130}$ 


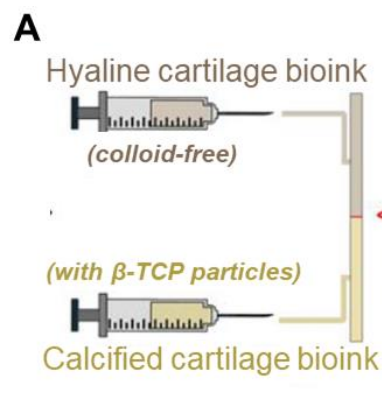

B

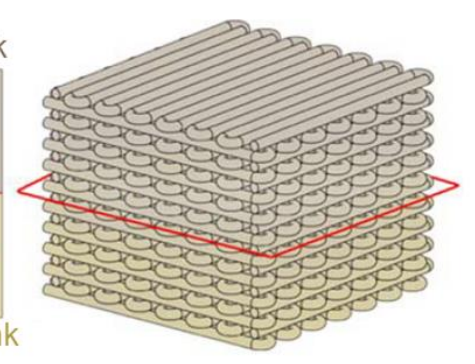

$3 D$ bioprinted

layered scaffold

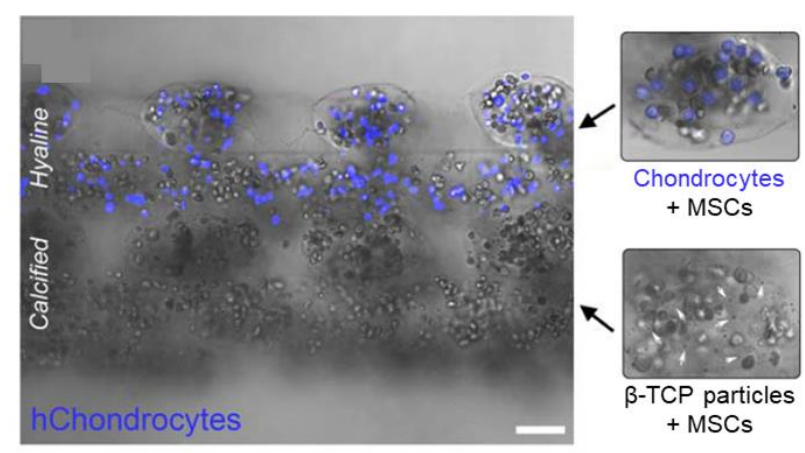

Figure 5: Cartilage printing: (A) Schematic drawing of a design of 3D bioprinted layered scaffold for the regeneration of the cartilaginous part of the osteochondral region. (B) Spatial distribution of two distinct bioinks and their components (cells and $\beta$-TCP crystals) in a bioprinted layered scaffold. CIOP Publishing. Reproduced from ref ${ }^{98}$, Copyright 2017, with permission. All right reserved.

Particles for drug release. Some nanoparticles were introduced in bioinks exclusively for their ability to deliver chemical species that contributed to the formation of healthy tissues. In the case of cartilage printing, PLGA microspheres containing either TGF- $\beta 3$ or the growth factor CTGF (connective tissue growth factor) were included in two separate bioinks. ${ }^{102}$ The combined printing of these inks allowed for the fabrication of anisotropic bioconstructs in which MSCs could differentiate either in "classical" chondrocytes or fibro-chondrocytes depending on the released active species (TGF- $\beta 3$ and CTGF, respectively). These different phenotypes produced distinct ECM components (Collagen type II and I, respectively) leading to anisotropic tissues resembling 
the native meniscus. Printed in the form of meniscus inside a supportive PCL scaffold, this biomimetic tissues were transplanted into goat knees where they provided long-term chondroprotection. A similar use of PLGA nanoparticles containing growth factors was reported for the stereolithographic printing of scaffolds for osteochondral regeneration. ${ }^{131}$

Other types of particle suspensions were added to bioinks for cartilage printing. Recently, an attempt was made at using silica nanoparticles $(20-50 \mathrm{~nm})$ but their influence on chondrocyte proliferation was found to be negligible. ${ }^{37}$ Large allograft cartilage fragments (few micrometers to hundreds of micrometers) were also included in composite bioinks. ${ }^{101}$ The chondrocytes in these composite bioinks proliferated quickly to reach a cell density similar to that of native cartilage after 8 weeks of maturation in chondrogenic medium. In addition, a cartilaginous matrix was produced which extent could be significantly increased by the addition of transforming growth factor beta-3 (TGF- $\beta 3$ ) in the culture medium.

\subsection{Electroactive tissue printing}

Electroactive tissues, like cardiac, muscle and neural tissues, respond to pulsatile or abrupt electrical stimuli. ${ }^{132}$ For the bioprinting of such tissues, conductive nanoparticles can be included in bioinks that would in turn promote electroactive tissue formation while allowing for their culture under electrical stimulation. ${ }^{133}$

Carbon-based colloids. Graphene and graphene oxide particles as well as carbon nanotubes (CNTs) have been used for the printing of electroactive tissues due to their conductive properties. For instance, micron sized graphene and graphene oxide particles were included in bioinks for neural tissue printing and were found to enhance the oxygen metabolism and the differentiation of neural stem cells (NSCs). ${ }^{106}$ Similarly, CNTs, which consist in rolled layers of sp2 bonded carbon (diameter $\approx 30 \mathrm{~nm}$, length $0.01-20 \mu \mathrm{m}),{ }^{134,135}$ were used to fabricate neural reconstruction scaffold 
by stereoligthography. ${ }^{134}$ These scaffold promoted NSC proliferation and early neuronal differentiation. In this conductive support, electrical stimulation of the cell-seeded material enhanced neural maturity and neurite outgrowth. CNTs were also employed in the bioprinting of supportive cardiac patch and imparted improved electrical and mechanical behavior to the printed material while fostering the proliferation and differentiation of coronary artery endothelial cells. ${ }^{104}$

Conductive polymer particles. The addition, in bioink formulations, of conductive nanoparticles made of polymers such as PEDOT:PSS (poly(3,4-ethylenedioxythiophene): polystyrene sulfonate) was also investigated for electroactive tissue printing. These polymeric nanoparticles $(<200 \mathrm{~nm})$ were able to increase both the conductivity and the printing fidelity of the bioink. ${ }^{103}$ After printing, they contributed to the growth of muscle cells by ensuring a high cell viability as well as an early differentiation in myotubes. In addition, their biodegradation and biocompatibility was confirmed by subcutaneous implantation in rats. ${ }^{103}$

Gold nanoparticles. Conductive Gold nanorods (30-40 nm) printed with a polymer matrix containing cardiac fibroblasts and cardiomyocyte were found to contribute to cell adhesion, and organization. ${ }^{105}$ These colloids created conductive bridges across the matrix which promoted electrical propagation and participated to the functional differentiation of cells (which expressed higher levels of gap junction proteins, as seen in Figure 6-A). Hence, the so-printed cells exhibited higher synchronized contractile frequency than those printed without nanorods (Figure 6-B). 
A Cardiac cells in GelMA/alginate bioink

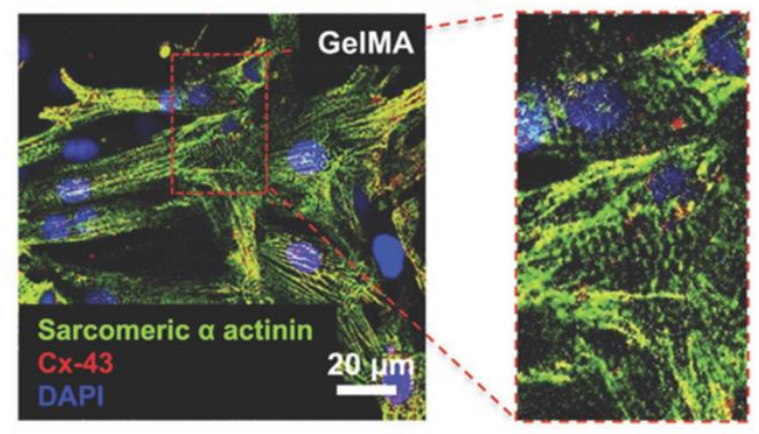

B

Cardiac cells in GelMA/gold nanorods composite bioink

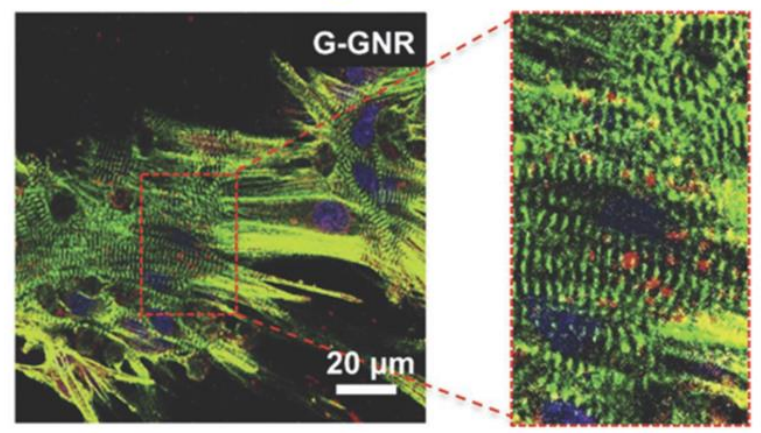

C

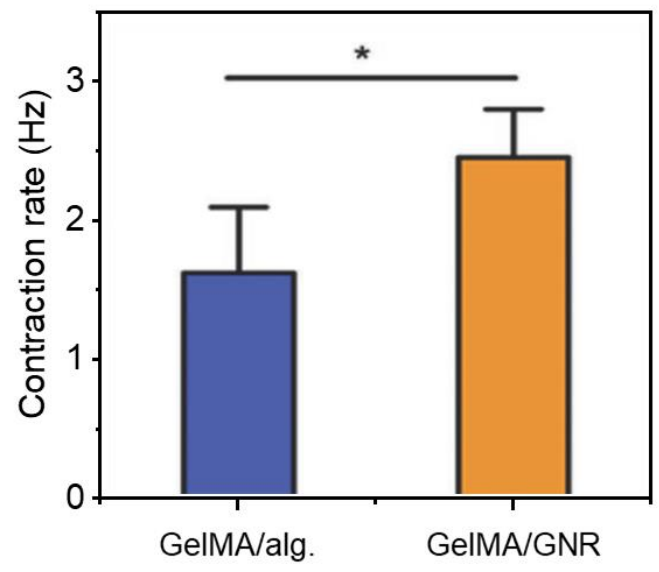

Figure 6: Cardiac tissue printing: (A) Microscopic observation of immunostained cardiac cells in printed constructs showing that, in a GelMA-based bioink containing gold nanorods (GNR), cells express higher levels of gap junction proteins than in the pure Gel-MA/alginate one. (B) Spontaneous beating rates of the GelMA/alginate bioink and GelMA/GNR composite bioink printed constructs. Reproduced from ref ${ }^{105}$. Copyright 2017 , with permission from WILEY-VCH Verlag. 


\subsection{Vascular tissue printing}

Vascularization of printed tissues is crucial to ascertain their long term viability and function. In that context, several strategies have been developed to print vascular tissues or to induce vasculogenesis within printed tissue constructs. ${ }^{33}, 35$ Systems based on composite bioprinted materials were also described with a focus on the contribution of the embedded colloids to the strengthening of the final tissue construct, yielding higher elastic moduli. Indeed, fine tubular structures, obtained by coaxial printing of a bioink containing $0.5 \%$ to $1 \%(\mathrm{w} / \mathrm{v}) \mathrm{CNTs}$, ${ }^{61}$ displayed elastic moduli $(150-700 \mathrm{kPa})$ resembling those of native vascular tissues $(100-1000 \mathrm{kPa}){ }^{136}$ Nonetheless, CNT-induced toxicity was found to cause cell damage and to hinder the production of ECM in these materials. Correspondingly, CNT-loaded biomaterial inks were also used to print cylindrical scaffold which were subsequently seeded with cells. ${ }^{66}$ The mechanical properties of these synthetic vessels were also very similar to biological ones (elastic moduli in the range 200$800 \mathrm{kPa})$. But the presence of CNTs induced a loss in cell adhesion and reduced viability. This result emphasizes the need to employ other nanomaterials able to maintain the mechanical response while ensuring an enhanced biocompatibility with vascular cell types.

Another indirect approach has been developed to design vascular tissues from composite bioinks. As mentioned previously (section 3.1), Byambaa et al reported the bioprinting of a nanoclay-loaded osteogenic hydrogel scaffolds surrounding a degradable hydrogel containing

endothelial cells (HUVEC).$^{90}$ In this sophisticated printed construct, the controlled degradation of the sacrificial hydrogel, combined with the progressive osteogenic differentiation of cells, yielded bone tissues that were vascularized by perfusable conduits. 


\subsection{Printing of other tissues}

Composite bioink formulations were also engineered for the printing of other tissue types. However, in these studies, colloids were included for their impact on the bioink rheology rather than for their influence on tissue formation. For instance, adipose tissue printing was performed with a bioink containing MSCs, hyaluronic acid and nanocellulose. ${ }^{107}$ Owing to the presence of nanocellulose, the rheological properties of the bioink allowed for optimized printing at low shear stress leading to outstanding cell viability (95\% after 1 week). The final printed material produced better adipogenic differentiation and more mature phenotype than 2D culture systems but the effect of nanocellulose on cellular growth was not investigated. In a similar way, a bioink made of cellulose nanocrystals (CNCs) and an alginate matrix was printed with fibroblasts and hepatoma cells to fabricate liver-mimetic tissues ${ }^{47} \mathrm{CNCs}$ were instrumental in tailoring the shear thinning properties of the bioink to guarantee a satisfactory post-printing cell viability. Nevertheless, the influence of CNCs on the cell growth and differentiation was not studied.

\section{INSIGHTS INTO THE SELECTION OF COLLOIDAL MATERIALS FOR COMPOSITE BIOINKS}

As exposed in this manuscript, composite bioinks hold great promises for the extrusion-based printing of biomimetic tissues of different types. However, selecting the appropriate colloidal materials that would simultaneously improve the printability, strengthen the mechanical properties and enhance the bioactivity of bioinks, is a challenging work. In this perspective, one should consider the specific interactions of colloidal particles with both the polymer matrix and the targeted cell lines. This is particularly demanding since these interactions depends on the particle composition, its surface chemistry, its size, its morphology and its functionality. 
On the one hand, the selection of a colloid type capable of interacting with the polymer chains in the bioink can be relatively simple, as many colloids can create weak crosslinks with various biomacromolecules through electrostatic or van der Waals interactions (as mentioned in section 2.2.). However, it is important to adjust the particle size and polymer chain length in order to (i) avoid a scenario where large particles are coated by short polymer chains instead of being bridged by them, and (ii) ensure the homogeneous distribution of the particles within the polymer matrix and prevent particle aggregation which decreases the interacting surface of colloids and weakens the physical network. For example, this has been achieved experimentally by introducing silica nanoparticles of intermediate size (diameter of $41 \mathrm{~nm}$ instead of 108 or $25 \mathrm{~nm}$ ) in a polymer precursor solution based on gellan and short alginate chains $(81 \mathrm{~kg} / \mathrm{mol}) \cdot{ }^{37}$ In addition, the introduction of colloids in a bioink formulation should be followed by a thorough physicochemical characterization of the resulting composite bioink. The key rheological characteristics (low shear viscosity, shear thinning properties, yield stress, shear recovery) should be evaluated and the printing parameters (printing speed, printing pressure, nozzle size and geometry) need to be optimized in order to tune the flow profile and restrain the shear stress on the printed cells.

On the other hand, in order to choose a colloidal species that will enhance the proliferation and differentiation of a targeted cell line, one can rely on the recently published works summarized in Section 3 and Table 3. Nevertheless, a crucial issue that needs to be carefully considered is the toxicity of the selected colloidal particles. The cytotoxicity of colloids depends on their chemical composition, their size, their morphology, their concentration and the type of cells they are interacting with. ${ }^{137-139}$ This means that biocompatibility and bioactivity of a given colloidal material cannot be inferred from studies using bulk materials or colloids with a similar composition but a different morphology (as in the case of HAp mentioned in section 3.1.), or else from results 
obtained on different cell lines. Hence, although it is useful to base the design of composite bioinks on existing knowledge about particle toxicity, ${ }^{139}$ it remains necessary to assess the toxicity of the selected colloid type on the targeted cell line prior to printing, ideally both in the presence and the absence of the polymer matrix. This step can be performed with an array of colloidal materials of the same composition but with different morphology/size so as to choose the best candidate for introduction in the bioink. Subsequently, the viability and proliferation of cells encapsulated in the composite bioink must be carefully monitored immediately after printing as well as during the subsequent maturation phase. It is also advisable to compare these results with those obtained in colloid-free formulations. This methodology, while being demanding, is necessary to evaluate the biocompatibility of the composite bioinks and to decorrelate the toxicity related to the embedded particles from the damages caused by the printing process. In a similar manner, it is also necessary to investigate the impact of the crosslinking method (UV treatment or introduction of chemical or physical crosslinkers as mentioned in section 2.2.) on the viability of the selected cells, ${ }^{140}$ especially since this effect depends on the cell type. ${ }^{54,141}$ Another related issue concerns the fate of the embedded colloids in the body. If some of the cited composite materials are easily degraded into biocompatible chemical species ( $\beta$-TCP, nanoclay), ${ }^{119,}{ }^{124}$ others (nGO, CNT and GNR) are not resorbed in vivo. ${ }^{105,119,142}$ Accordingly, it is indispensable to either identify their elimination pathways ${ }^{105}$ or develop new methods to ensure their physiological degradation. ${ }^{142}$

Finally, as evidenced by the different references listed in Table 1, 2 and 3 of this manuscript, studies on composite bioinks most often concentrate either on the physicochemical characterization of bioinks or on the evaluation of their potential as support for tissue formation. However, considering that colloids influence both the printability of bioinks and the growth of 
encapsulated cells, it appears necessary to study composite bioinks concurrently from a material science perspective and from a tissue engineering point of view.

\section{FUTURE PERSPECTIVES}

Apart from the remaining challenges presented above, composite bioinks also present fascinating opportunities for the fabrication of original tissue constructs. For instance, composite bioinks are presented as outstanding candidates for 4D bioprinting. ${ }^{143,144}$ This emerging technique consists in printing biomaterials acting as actuators, i.e. having the ability to change shape in response to one stimulus. Such deformable constructs would mimic more accurately the structural dynamics of living tissues. The potential of composite bioinks for this application was brought to light by the seminal work of Gladman and co-workers who reported the printing of CNF-laden gels with shape morphing abilities. ${ }^{145}$ In the printed construct, the cellulosic nanofibers were aligned and could restrain the swelling of the gel in the direction of their alignment, therefore forcing the gel to expand in the other directions. Building on this observation, the printing of complex patterns with alternate fiber orientations led to hydrogel scaffolds which transformed into sophisticated 3D shapes upon immersion in water. The transposition of this approach to cell-laden printable biomaterials has yet to be achieved and would represent a key development in the field of tissue engineering. Recently, Betsch and coworkers designed a collagen-based bioink containing iron oxide nanoparticles which could cause the alignment of collagen fibers under a magnetic field. ${ }^{146}$ This structural organization affected the mechanical properties of the gel and increased the production of ECM by encapsulated cells. However, no shape-morphing ability was reported. Consequently, groundbreaking advances remain to be made in this very promising field. 
Finally, the future of composite bioinks may reside in the combination of several colloid types within the same formulation so as to increase its versatility by summing the specific functionalities of the different particles. A recent example of this approach was given by Ojansivu and coworkers who successfully associated, in the same composite bioink, CNFs as rheology modifiers and bioactive glass particles for their osteogenic properties. ${ }^{54}$ More generally, the co-printing of several bioinks with different compositions (with or without embedded colloids) and properties (mechanical response, bioactivity, etc) could greatly enhance biomimicry and ultimately lead to implantable tissue grafts. Indeed, such multiple-bioink printing would allow for combining the controlled distribution of mechanical stiffness, the selective promotion of precursor cells growth by colloids, and the localized delivery of drugs and or/ growth factors to enhance tissue production.

\section{AUTHOR INFORMATION}

\section{Corresponding Author}

*Rachel Auzély-Velty, rachel.auzely@cermav.cnrs.fr

*Raphael Michel, raphael.michel@cermav.cnrs.fr

\section{Author Contributions}

The manuscript was written through contributions of all authors. All authors have given approval to the final version of the manuscript.

\section{Notes}

The authors declare no conflict of interest.

\section{ACKNOWLEDGMENT}


We gratefully acknowledge the Institut Carnot Polynat (CARN 0007-01) for postdoctoral funding.

\section{REFERENCES}

1. Derakhshanfar, S.; Mbeleck, R.; Xu, K.; Zhang, X.; Zhong, W.; Xing, M., 3D bioprinting for biomedical devices and tissue engineering: A review of recent trends and advances. Bioactive Materials 2018, 3 (2), 144-156.

2. Lee, J. M.; Yeong, W. Y., Design and Printing Strategies in 3D Bioprinting of CellHydrogels: A Review. Advanced Healthcare Materials 2016, 5 (22), 2856-2865.

3. Murphy, S. V.; Atala, A., 3D bioprinting of tissues and organs. Nature Biotechnology 2014, $32(8), 773-785$.

4. Groll, J.; Boland, T.; Blunk, T.; Burdick, J. A.; Cho, D.-W.; Dalton, P. D.; Derby, B.; Forgacs, G.; Li, Q.; Mironov, V. A.; Moroni, L.; Nakamura, M.; Shu, W.; Takeuchi, S.; Vozzi, G.; Woodfield, T. B. F.; Xu, T.; Yoo, J. J.; Malda, J., Biofabrication: reappraising the definition of an evolving field. Biofabrication 2016, 8 (1), 013001.

5. Moroni, L.; Boland, T.; Burdick, J. A.; De Maria, C.; Derby, B.; Forgacs, G.; Groll, J.; Li, Q.; Malda, J.; Mironov, V. A.; Mota, C.; Nakamura, M.; Shu, W.; Takeuchi, S.; Woodfield, T. B. F.; Xu, T.; Yoo, J. J.; Vozzi, G., Biofabrication: A Guide to Technology and Terminology. Trends in Biotechnology 2018, 36 (4), 384-402.

6. Bishop, E. S.; Mostafa, S.; Pakvasa, M.; Luu, H. H.; Lee, M. J.; Wolf, J. M.; Ameer, G. A.; He, T.-C.; Reid, R. R., 3-D bioprinting technologies in tissue engineering and regenerative medicine: Current and future trends. Genes \& Diseases 2017, 4 (4), 185-195. 
7. Hölzl, K.; Lin, S.; Tytgat, L.; Van Vlierberghe, S.; Gu, L.; Ovsianikov, A., Bioink properties before, during and after 3D bioprinting. Biofabrication 2016, 8 (3), 032002.

8. Jungst, T.; Smolan, W.; Schacht, K.; Scheibel, T.; Groll, J., Strategies and Molecular Design Criteria for 3D Printable Hydrogels. Chemical Reviews 2016, 116 (3), 1496-1539.

9. Paxton, N.; Smolan, W.; Böck, T.; Melchels, F.; Groll, J.; Jungst, T., Proposal to assess printability of bioinks for extrusion-based bioprinting and evaluation of rheological properties governing bioprintability. Biofabrication 2017, 9 (4), 044107.

10. Sun, W.; Starly, B.; Daly, A. C.; Burdick, J. A.; Groll, J.; Skeldon, G.; Shu, W.; Sakai, Y.; Shinohara, M.; Nishikawa, M.; Jang, J.; Cho, D.-W.; Nie, M.; Takeuchi, S.; Ostrovidov, S.; Khademhosseini, A.; Kamm, R. D.; Mironov, V.; Moroni, L.; Ozbolat, I. T., The bioprinting roadmap. Biofabrication 2020, 12 (2), 022002.

11. Chimene, D.; Kaunas, R.; Gaharwar, A. K., Hydrogel Bioink Reinforcement for Additive Manufacturing: A Focused Review of Emerging Strategies. Advanced Materials 2020, 32 (1), 1902026.

12. Melchels, F. P. W.; Dhert, W. J. A.; Hutmacher, D. W.; Malda, J., Development and characterisation of a new bioink for additive tissue manufacturing. Journal of Materials Chemistry B 2014, 2 (16), 2282-2289.

13. Ning, L.; Guillemot, A.; Zhao, J.; Kipouros, G.; Chen, X., Influence of Flow Behavior of Alginate-Cell Suspensions on Cell Viability and Proliferation. Tissue Engineering Part C: Methods 2016, 22 (7), 652-662. 
14. Mouser, V. H. M.; Melchels, F. P. W.; Visser, J.; Dhert, W. J. A.; Gawlitta, D.; Malda, J., Yield stress determines bioprintability of hydrogels based on gelatin-methacryloyl and gellan gum for cartilage bioprinting. Biofabrication 2016, 8 (3), 035003.

15. Chimene, D.; Peak, C. W.; Gentry, J. L.; Carrow, J. K.; Cross, L. M.; Mondragon, E.; Cardoso, G. B.; Kaunas, R.; Gaharwar, A. K., Nanoengineered Ionic-Covalent Entanglement (NICE) Bioinks for 3D Bioprinting. ACS Applied Materials \& Interfaces 2018, 10 (12), 99579968.

16. Foster, A. A.; Marquardt, L. M.; Heilshorn, S. C., The Diverse Roles of Hydrogel Mechanics in Injectable Stem Cell Transplantation. Curr Opin Chem Eng 2017, 15, 15-23.

17. Li, H.; Tan, Y. J.; Leong, K. F.; Li, L., 3D Bioprinting of Highly Thixotropic Alginate/Methylcellulose Hydrogel with Strong Interface Bonding. ACS Applied Materials \& Interfaces 2017, 9 (23), 20086-20097.

18. Knowlton, S.; Yenilmez, B.; Anand, S.; Tasoglu, S., Photocrosslinking-based bioprinting: Examining crosslinking schemes. Bioprinting 2017, 5, 10-18.

19. Rastogi, P.; Kandasubramanian, B., Review of alginate-based hydrogel bioprinting for application in tissue engineering. Biofabrication 2019, 11 (4), 042001.

20. Wang, X.; Ao, Q.; Tian, X.; Fan, J.; Tong, H.; Hou, W.; Bai, S., Gelatin-Based Hydrogels for Organ 3D Bioprinting. Polymers 2017, 9 (9), 401.

21. Klein, A.; Whitten, P. G.; Resch, K.; Pinter, G., Nanocomposite hydrogels: Fracture toughness and energy dissipation mechanisms. Journal of Polymer Science Part B: Polymer Physics 2015, 53 (24), 1763-1773. 
22. Yang, J.; Han, C.-R.; Duan, J.-F.; Xu, F.; Sun, R.-C., Mechanical and Viscoelastic Properties of Cellulose Nanocrystals Reinforced Poly(ethylene glycol) Nanocomposite Hydrogels. ACS Applied Materials \& Interfaces 2013, 5 (8), 3199-3207.

23. Chang, C.-W.; van Spreeuwel, A.; Zhang, C.; Varghese, S., PEG/clay nanocomposite hydrogel: a mechanically robust tissue engineering scaffold. Soft Matter 2010, 6 (20), 5157-5164.

24. Mehrali, M.; Thakur, A.; Pennisi, C. P.; Talebian, S.; Arpanaei, A.; Nikkhah, M.; Dolatshahi-Pirouz, A., Nanoreinforced Hydrogels for Tissue Engineering: Biomaterials that are Compatible with Load-Bearing and Electroactive Tissues. Advanced Materials 2017, 29 (8), 1603612.

25. Biondi, M.; Borzacchiello, A.; Mayol, L.; Ambrosio, L., Nanoparticle-Integrated Hydrogels as Multifunctional Composite Materials for Biomedical Applications. Gels 2015, 1 (2), $162-178$.

26. Chimene, D.; Alge, D. L.; Gaharwar, A. K., Two-Dimensional Nanomaterials for Biomedical Applications: Emerging Trends and Future Prospects. Advanced Materials 2015, 27 (45), 7261-7284.

27. Eswaramoorthy, S. D.; Ramakrishna, S.; Rath, S. N., Recent advances in three-dimensional bioprinting of stem cells. Journal of Tissue Engineering and Regenerative Medicine 2019, 13 (6), 908-924.

28. Jang, T.-S.; Jung, H.-D.; Pan, H. M.; Han, W. T.; Chen, S.; Song, J., 3D printing of hydrogel composite systems: Recent advances in technology for tissue engineering. International Journal of Bioprinting 2018, 4 (1), 126. 
29. Athukoralalage, S. S.; Balu, R.; Dutta, K. N.; Roy Choudhury, N., 3D Bioprinted Nanocellulose-Based Hydrogels for Tissue Engineering Applications: A Brief Review. Polymers 2019, $11(5), 898$.

30. Chinga-Carrasco, G., Potential and Limitations of Nanocelluloses as Components in Biocomposite Inks for Three-Dimensional Bioprinting and for Biomedical Devices. Biomacromolecules 2018, 19 (3), 701-711.

31. Afewerki, S.; Magalhães, L. S. S. M.; Silva, A. D. R.; Stocco, T. D.; Silva Filho, E. C.; Marciano, F. R.; Lobo, A. O., Bioprinting a Synthetic Smectic Clay for Orthopedic Applications. Advanced Healthcare Materials 2019, 8 (13), 1900158.

32. Ashammakhi, N.; Hasan, A.; Kaarela, O.; Byambaa, B.; Sheikhi, A.; Gaharwar, A. K.; Khademhosseini, A., Advancing Frontiers in Bone Bioprinting. Advanced Healthcare Materials 2019, $8(7), 1801048$.

33. Datta, P.; Ayan, B.; Ozbolat, I. T., Bioprinting for vascular and vascularized tissue biofabrication. Acta Biomaterialia 2017, 51, 1-20.

34. De Mori, A.; Peña Fernández, M.; Blunn, G.; Tozzi, G.; Roldo, M., 3D Printing and Electrospinning of Composite Hydrogels for Cartilage and Bone Tissue Engineering. Polymers 2018, $10(3), 285$.

35. Miri, A. K.; Khalilpour, A.; Cecen, B.; Maharjan, S.; Shin, S. R.; Khademhosseini, A., Multiscale bioprinting of vascularized models. Biomaterials 2019, 198, 204-216.

36. Groll, J.; Burdick, J. A.; Cho, D. W.; Derby, B.; Gelinsky, M.; Heilshorn, S. C.; Jüngst, T.; Malda, J.; Mironov, V. A.; Nakayama, K.; Ovsianikov, A.; Sun, W.; Takeuchi, S.; Yoo, J. J.; 
Woodfield, T. B. F., A definition of bioinks and their distinction from biomaterial inks. Biofabrication 2018, 11 (1), 013001.

37. Lee, M.; Bae, K.; Guillon, P.; Chang, J.; Arlov, Ø.; Zenobi-Wong, M., Exploitation of Cationic Silica Nanoparticles for Bioprinting of Large-Scale Constructs with High Printing Fidelity. ACS Applied Materials \& Interfaces 2018, 10 (44), 37820-37828.

38. Chen, R.-D.; Huang, C.-F.; Hsu, S.-h., Composites of waterborne polyurethane and cellulose nanofibers for 3D printing and bioapplications. Carbohydrate Polymers 2019, 212, 7588.

39. Roopavath, U. K.; Soni, R.; Mahanta, U.; Deshpande, A. S.; Rath, S. N., 3D printable SiO2 nanoparticle ink for patient specific bone regeneration. RSC Advances 2019, 9 (41), 23832-23842.

40. Wilson, S. A.; Cross, L. M.; Peak, C. W.; Gaharwar, A. K., Shear-Thinning and ThermoReversible Nanoengineered Inks for 3D Bioprinting. ACS Applied Materials \& Interfaces 2017, 9 (50), 43449-43458.

41. Wu, X.; Chen, K.; Zhang, D.; Xu, L.; Yang, X., Study on the technology and properties of 3D bioprinting SF/GT/n-HA composite scaffolds. Materials Letters 2019, 238, 89-92.

42. Shin, S.; Park, S.; Park, M.; Jeong, E.; Na, K.; Youn, H. J.; Hyun, J., Cellulose Nanofibers for the Enhancement of Printability of Low Viscosity Gelatin Derivatives. BioResources 2017, 12 (2), 2941-2954.

43. Nadernezhad, A.; Caliskan, O. S.; Topuz, F.; Afghah, F.; Erman, B.; Koc, B., Nanocomposite Bioinks Based on Agarose and 2D Nanosilicates with Tunable Flow Properties and Bioactivity for 3D Bioprinting. ACS Applied Bio Materials 2019, 2 (2), 796-806. 
44. Chimene, D.; Miller, L.; Cross, L.; Jaiswal, M. K.; Singh, I.; Gaharwar, A. K., Nanoengineered Osteoinductive Bioink for 3D Bioprinting Bone Tissue. ACS Applied Materials \& Interfaces 2020, 12 (14), 15976-15988.

45. Gao, Q.; Niu, X.; Shao, L.; Zhou, L.; Lin, Z.; Sun, A.; Fu, J.; Chen, Z.; Hu, J.; Liu, Y.; He, Y., 3D printing of complex GelMA-based scaffolds with nanoclay. Biofabrication 2019, 11 (3), 035006.

46. Peak, C. W.; Stein, J.; Gold, K. A.; Gaharwar, A. K., Nanoengineered Colloidal Inks for 3D Bioprinting. Langmuir 2018, 34 (3), 917-925.

47. Wu, Y.; Lin, Z. Y.; Wenger, A. C.; Tam, K. C.; Tang, X., 3D bioprinting of liver-mimetic construct with alginate/cellulose nanocrystal hybrid bioink. Bioprinting 2018, 9, 1-6.

48. Topuz, F.; Nadernezhad, A.; Caliskan, O. S.; Menceloglu, Y. Z.; Koc, B., Nanosilicate embedded agarose hydrogels with improved bioactivity. Carbohydrate Polymers 2018, 201, 105112.

49. Lepowsky, E.; Muradoglu, M.; Tasoglu, S., Towards preserving post-printing cell viability and improving the resolution: Past, present, and future of 3D bioprinting theory. Bioprinting 2018, $11, \mathrm{e} 00034$.

50. Müller, M.; Öztürk, E.; Arlov, Ø.; Gatenholm, P.; Zenobi-Wong, M., Alginate SulfateNanocellulose Bioinks for Cartilage Bioprinting Applications. Annals of Biomedical Engineering 2017, 45 (1), 210-223. 
51. Nair, K.; Gandhi, M.; Khalil, S.; Yan, K. C.; Marcolongo, M.; Barbee, K.; Sun, W., Characterization of cell viability during bioprinting processes. Biotechnology Journal 2009, 4 (8), $1168-1177$.

52. Alcala-Orozco, C. R.; Mutreja, I.; Cui, X.; Kumar, D.; Hooper, G. J.; Lim, K. S.; Woodfield, T. B. F., Design and characterisation of multi-functional strontium-gelatin nanocomposite bioinks with improved print fidelity and osteogenic capacity. Bioprinting 2020, $18, \mathrm{e} 00073$.

53. Wenz, A.; Janke, K.; Hoch, E.; Tovar Günter, E. M.; Borchers, K.; Kluger Petra, J., Hydroxyapatite-modified gelatin bioinks for bone bioprinting. BioNanoMaterials 2016, 17 (3-4), 179.

54. Ojansivu, M.; Rashad, A.; Ahlinder, A.; Massera, J.; Mishra, A.; Syverud, K.; FinneWistrand, A.; Miettinen, S.; Mustafa, K., Wood-based nanocellulose and bioactive glass modified gelatin-alginate bioinks for 3D bioprinting of bone cells. Biofabrication 2019, 11 (3), 035010.

55. Marquardt, L. M.; Heilshorn, S. C., Design of Injectable Materials to Improve Stem Cell Transplantation. Current Stem Cell Reports 2016, 2 (3), 207-220.

56. Snyder, J.; Rin Son, A.; Hamid, Q.; Wang, C.; Lui, Y.; Sun, W., Mesenchymal stem cell printing and process regulated cell properties. Biofabrication 2015, 7 (4), 044106.

57. Can, V.; Okay, O., Shake gels based on Laponite-PEO mixtures: effect of polymer molecular weight. Designed Monomers and Polymers 2005, 8 (5), 453-462. 
58. Smith, J. S.; Bedrov, D.; Smith, G. D., A molecular dynamics simulation study of nanoparticle interactions in a model polymer-nanoparticle composite. Composites Science and Technology 2003, 63 (11), 1599-1605.

59. Kosik-Kozioł, A.; Costantini, M.; Bolek, T.; Szöke, K.; Barbetta, A.; Brinchmann, J.; Święszkowski, W., PLA short sub-micron fiber reinforcement of 3D bioprinted alginate constructs for cartilage regeneration. Biofabrication 2017, 9 (4), 044105.

60. Zhou, X.; Zhu, W.; Nowicki, M.; Miao, S.; Cui, H.; Holmes, B.; Glazer, R. I.; Zhang, L. G., 3D Bioprinting a Cell-Laden Bone Matrix for Breast Cancer Metastasis Study. ACS Applied Materials \& Interfaces 2016, 8 (44), 30017-30026.

61. Dolati, F.; Yu, Y.; Zhang, Y.; De Jesus, A. M.; Sander, E. A.; Ozbolat, I. T., In vitro evaluation of carbon-nanotube-reinforced bioprintable vascular conduits. Nanotechnology 2014, $25(14), 145101-145101$.

62. Rose, S.; Prevoteau, A.; Elzière, P.; Hourdet, D.; Marcellan, A.; Leibler, L., Nanoparticle solutions as adhesives for gels and biological tissues. Nature 2014, 505 (7483), 382-385.

63. Santore, M. M., Dynamics in adsorbed homopolymer layers: Understanding complexity from simple starting points. Current Opinion in Colloid \& Interface Science 2005, 10 (3), 176183.

64. Wüst, S.; Godla, M. E.; Müller, R.; Hofmann, S., Tunable hydrogel composite with twostep processing in combination with innovative hardware upgrade for cell-based three-dimensional bioprinting. Acta Biomaterialia 2014, 10 (2), 630-640. 
65. Hu, X.; Man, Y.; Li, W.; Li, L.; Xu, J.; Parungao, R.; Wang, Y.; Zheng, S.; Nie, Y.; Liu, T.; Song, K., 3D Bio-Printing of CS/Gel/HA/Gr Hybrid Osteochondral Scaffolds. Polymers 2019, $11(10)$

66. Li, L.; Qin, S.; Peng, J.; Chen, A.; Nie, Y.; Liu, T.; Song, K., Engineering gelatin-based alginate/carbon nanotubes blend bioink for direct 3D printing of vessel constructs. International Journal of Biological Macromolecules 2020, 145, 262-271.

67. Annabi, N.; Tamayol, A.; Shin, S. R.; Ghaemmaghami, A. M.; Peppas, N. A.; Khademhosseini, A., Surgical materials: Current challenges and nano-enabled solutions. Nano Today 2014, 9 (5), 574-589.

68. Bertlein, S.; Brown, G.; Lim, K. S.; Jungst, T.; Boeck, T.; Blunk, T.; Tessmar, J.; Hooper, G. J.; Woodfield, T. B. F.; Groll, J., Thiol-Ene Clickable Gelatin: A Platform Bioink for Multiple 3D Biofabrication Technologies. Advanced Materials 2017, 29 (44), 1703404.

69. Daly, A. C.; Cunniffe, G. M.; Sathy, B. N.; Jeon, O.; Alsberg, E.; Kelly, D. J., 3D Bioprinting of Developmentally Inspired Templates for Whole Bone Organ Engineering. Advanced Healthcare Materials 2016, 5 (18), 2353-2362.

70. Gaharwar, A. K.; Rivera, C.; Wu, C.-J.; Chan, B. K.; Schmidt, G., Photocrosslinked nanocomposite hydrogels from PEG and silica nanospheres: Structural, mechanical and cell adhesion characteristics. Materials Science and Engineering: C 2013, 33 (3), 1800-1807.

71. Schmidt, S.; Madaboosi, N.; Uhlig, K.; Köhler, D.; Skirtach, A.; Duschl, C.; Möhwald, H.; Volodkin, D. V., Control of Cell Adhesion by Mechanical Reinforcement of Soft Polyelectrolyte Films with Nanoparticles. Langmuir 2012, 28 (18), 7249-7257. 
72. Shin, S. R.; Bae, H.; Cha, J. M.; Mun, J. Y.; Chen, Y.-C.; Tekin, H.; Shin, H.; Farshchi, S.; Dokmeci, M. R.; Tang, S.; Khademhosseini, A., Carbon Nanotube Reinforced Hybrid Microgels as Scaffold Materials for Cell Encapsulation. ACS Nano 2012, 6 (1), 362-372.

73. Wenz, A.; Borchers, K.; Tovar, G. E. M.; Kluger, P. J., Bone matrix production in hydroxyapatite-modified hydrogels suitable for bone bioprinting. Biofabrication 2017, 9 (4), 044103.

74. Jia, J.; Richards, D. J.; Pollard, S.; Tan, Y.; Rodriguez, J.; Visconti, R. P.; Trusk, T. C.; Yost, M. J.; Yao, H.; Markwald, R. R.; Mei, Y., Engineering alginate as bioink for bioprinting. Acta biomaterialia 2014, 10 (10), 4323-4331.

75. Baker, B. M.; Chen, C. S., Deconstructing the third dimension - how 3D culture microenvironments alter cellular cues. Journal of Cell Science 2012, 125 (13), 3015.

76. Chaudhuri, O.; Gu, L.; Klumpers, D.; Darnell, M.; Bencherif, S. A.; Weaver, J. C.; Huebsch, N.; Lee, H.-p.; Lippens, E.; Duda, G. N.; Mooney, D. J., Hydrogels with tunable stress relaxation regulate stem cell fate and activity. Nature Materials 2015, 15, 326.

77. Engler, A. J.; Sen, S.; Sweeney, H. L.; Discher, D. E., Matrix Elasticity Directs Stem Cell Lineage Specification. Cell 2006, 126 (4), 677-689.

78. Lv, H.; Li, L.; Sun, M.; Zhang, Y.; Chen, L.; Rong, Y.; Li, Y., Mechanism of regulation of stem cell differentiation by matrix stiffness. Stem Cell Res Ther 2015, 6 (1), 103-103.

79. Shih, Y.-R. V.; Tseng, K.-F.; Lai, H.-Y.; Lin, C.-H.; Lee, O. K., Matrix stiffness regulation of integrin-mediated mechanotransduction during osteogenic differentiation of human mesenchymal stem cells. Journal of Bone and Mineral Research 2011, 26 (4), 730-738. 
80. Wen, J. H.; Vincent, L. G.; Fuhrmann, A.; Choi, Y. S.; Hribar, K. C.; Taylor-Weiner, H.; Chen, S.; Engler, A. J., Interplay of matrix stiffness and protein tethering in stem cell differentiation. Nature Materials 2014, 13 (10), 979-987.

81. Caliari, S. R.; Burdick, J. A., A practical guide to hydrogels for cell culture. Nat Methods 2016, $13(5), 405-414$.

82. Park, H.; Guo, X.; Temenoff, J. S.; Tabata, Y.; Caplan, A. I.; Kasper, F. K.; Mikos, A. G., Effect of swelling ratio of injectable hydrogel composites on chondrogenic differentiation of encapsulated rabbit marrow mesenchymal stem cells in vitro. Biomacromolecules 2009, 10 (3), $541-546$.

83. Kocen, R.; Gasik, M.; Gantar, A.; Novak, S., Viscoelastic behaviour of hydrogel-based composites for tissue engineering under mechanical load. Biomedical Materials 2017, 12 (2), 025004.

84. Bendtsen, S. T.; Quinnell, S. P.; Wei, M., Development of a novel alginate-polyvinyl alcohol-hydroxyapatite hydrogel for 3D bioprinting bone tissue engineered scaffolds. Journal of Biomedical Materials Research Part A 2017, 105 (5), 1457-1468.

85. Demirtaş, T. T.; Irmak, G.; Gümüşderelioğlu, M., A bioprintable form of chitosan hydrogel for bone tissue engineering. Biofabrication 2017, 9 (3), 035003.

86. Wang, X.-F.; Lu, P.-J.; Song, Y.; Sun, Y.-C.; Wang, Y.-G.; Wang, Y., Nano hydroxyapatite particles promote osteogenesis in a three-dimensional bio-printing construct consisting of alginate/gelatin/hASCs. RSC Advances 2016, 6 (8), 6832-6842. 
87. Kim, W.; Kim, G., Collagen/bioceramic-based composite bioink to fabricate a porous 3D hASCs-laden structure for bone tissue regeneration. Biofabrication 2019, 12 (1), 015007.

88. Wang, X.; Tolba, E.; Schröder, H. C.; Neufurth, M.; Feng, Q.; Diehl-Seifert, B.; Müller, W. E. G., Effect of Bioglass on Growth and Biomineralization of SaOS-2 Cells in Hydrogel after 3D Cell Bioprinting. PLOS ONE 2014, 9 (11), e112497.

89. Leite, Á. J.; Sarker, B.; Zehnder, T.; Silva, R.; Mano, J. F.; Boccaccini, A. R., Bioplotting of a bioactive alginate dialdehyde-gelatin composite hydrogel containing bioactive glass nanoparticles. Biofabrication 2016, 8 (3), 035005.

90. Byambaa, B.; Annabi, N.; Yue, K.; Trujillo-de Santiago, G.; Alvarez, M. M.; Jia, W.; Kazemzadeh-Narbat, M.; Shin, S. R.; Tamayol, A.; Khademhosseini, A., Bioprinted Osteogenic and Vasculogenic Patterns for Engineering 3D Bone Tissue. Advanced Healthcare Materials 2017, $6(16), 1700015$.

91. Cidonio, G.; Alcala-Orozco, C. R.; Lim, K. S.; Glinka, M.; Mutreja, I.; Kim, Y.-H.; Dawson, J. I.; Woodfield, T. B. F.; Oreffo, R. O. C., Osteogenic and angiogenic tissue formation in high fidelity nanocomposite Laponite-gelatin bioinks. Biofabrication 2019, 11 (3), 035027.

92. Cidonio, G.; Cooke, M.; Glinka, M.; Dawson, J. I.; Grover, L.; Oreffo, R. O. C., Printing bone in a gel: using nanocomposite bioink to print functionalised bone scaffolds. Materials Today Bio 2019, 4, 100028.

93. Choe, G.; Oh, S.; Seok, J. M.; Park, S. A.; Lee, J. Y., Graphene oxide/alginate composites as novel bioinks for three-dimensional mesenchymal stem cell printing and bone regeneration applications. Nanoscale 2019, 11 (48), 23275-23285. 
94. Jessop, Z. M.; Al-Sabah, A.; Gao, N.; Kyle, S.; Thomas, B.; Badiei, N.; Hawkins, K.; Whitaker, I. S., Printability of pulp derived crystal, fibril and blend nanocellulose-alginate bioinks for extrusion 3D bioprinting. Biofabrication 2019, 11 (4), 045006.

95. Markstedt, K.; Mantas, A.; Tournier, I.; Martínez Ávila, H.; Hägg, D.; Gatenholm, P., 3D Bioprinting Human Chondrocytes with Nanocellulose-Alginate Bioink for Cartilage Tissue Engineering Applications. Biomacromolecules 2015, 16 (5), 1489-1496.

96. Martínez Ávila, H.; Schwarz, S.; Rotter, N.; Gatenholm, P., 3D bioprinting of human chondrocyte-laden nanocellulose hydrogels for patient-specific auricular cartilage regeneration. Bioprinting 2016, 1-2, 22-35.

97. Nguyen, D.; Hägg, D. A.; Forsman, A.; Ekholm, J.; Nimkingratana, P.; Brantsing, C.; Kalogeropoulos, T.; Zaunz, S.; Concaro, S.; Brittberg, M.; Lindahl, A.; Gatenholm, P.; Enejder, A.; Simonsson, S., Cartilage Tissue Engineering by the 3D Bioprinting of iPS Cells in a Nanocellulose/Alginate Bioink. Scientific Reports 2017, 7 (1), 658.

98. Idaszek, J.; Costantini, M.; Karlsen, T. A.; Jaroszewicz, J.; Colosi, C.; Testa, S.; Fornetti, E.; Bernardini, S.; Seta, M.; Kasarełło, K.; Wrzesień, R.; Cannata, S.; Barbetta, A.; Gargioli, C.; Brinchman, J. E.; Święszkowski, W., 3D bioprinting of hydrogel constructs with cell and material gradients for the regeneration of full-thickness chondral defect using a microfluidic printing head. Biofabrication 2019, 11 (4), 044101.

99. Kosik-Kozioł, A.; Costantini, M.; Mróz, A.; Idaszek, J.; Heljak, M.; Jaroszewicz, J.; Kijeńska, E.; Szöke, K.; Frerker, N.; Barbetta, A.; Brinchmann, J. E.; Święszkowski, W., 3D bioprinted hydrogel model incorporating $\beta$-tricalcium phosphate for calcified cartilage tissue engineering. Biofabrication 2019, 11 (3), 035016. 
100. Fan, Y.; Shi, T.; Yue, X.; Sun, F.; Yao, D., 3D Composite Cell Printing Gelatin/Sodium Alginate/n-HAP Bioscaffold. Journal of Physics: Conference Series 2019, 1213, 042020.

101. Kesti, M.; Eberhardt, C.; Pagliccia, G.; Kenkel, D.; Grande, D.; Boss, A.; Zenobi-Wong, M., Bioprinting Complex Cartilaginous Structures with Clinically Compliant Biomaterials. Advanced Functional Materials 2015, 25 (48), 7406-7417.

102. Sun, Y.; You, Y.; Jiang, W.; Wu, Q.; Wang, B.; Dai, K., Generating ready-to-implant anisotropic menisci by 3D-bioprinting protein-releasing cell-laden hydrogel-polymer composite scaffold. Applied Materials Today 2019, 100469.

103. Spencer, A. R.; Shirzaei Sani, E.; Soucy, J. R.; Corbet, C. C.; Primbetova, A.; Koppes, R. A.; Annabi, N., Bioprinting of a Cell-Laden Conductive Hydrogel Composite. ACS Applied Materials \& Interfaces 2019, 11 (34), 30518-30533.

104. Izadifar, M.; Chapman, D.; Babyn, P.; Chen, X.; Kelly, M. E., UV-Assisted 3D Bioprinting of Nanoreinforced Hybrid Cardiac Patch for Myocardial Tissue Engineering. Tissue Engineering Part C: Methods 2017, 24 (2), 74-88.

105. Zhu, K.; Shin, S. R.; van Kempen, T.; Li, Y.-C.; Ponraj, V.; Nasajpour, A.; Mandla, S.; Hu, N.; Liu, X.; Leijten, J.; Lin, Y.-D.; Hussain, M. A.; Zhang, Y. S.; Tamayol, A.; Khademhosseini, A., Gold Nanocomposite Bioink for Printing 3D Cardiac Constructs. Advanced Functional Materials 2017, 27 (12), 1605352.

106. Huang, C.-T.; Kumar Shrestha, L.; Ariga, K.; Hsu, S.-h., A graphene-polyurethane composite hydrogel as a potential bioink for 3D bioprinting and differentiation of neural stem cells. Journal of Materials Chemistry B 2017, 5 (44), 8854-8864. 
107. Henriksson, I.; Gatenholm, P.; Hägg, D. A., Increased lipid accumulation and adipogenic gene expression of adipocytes in 3D bioprinted nanocellulose scaffolds. Biofabrication 2017, 9 (1), 015022 .

108. Giannoudis, P. V.; Dinopoulos, H.; Tsiridis, E., Bone substitutes: An update. Injury 2005, 36 (3, Supplement), 20-27.

109. Kim, J.; McBride, S.; Tellis, B.; Alvarez-Urena, P.; Song, Y.-H.; Dean, D. D.; Sylvia, V. L.; Elgendy, H.; Ong, J.; Hollinger, J. O., Rapid-prototyped PLGA/ $\beta-T C P /$ hydroxyapatite nanocomposite scaffolds in a rabbit femoral defect model. Biofabrication 2012, 4 (2), 025003.

110. Wang, Y.; Wu, S.; Kuss, M. A.; Streubel, P. N.; Duan, B., Effects of Hydroxyapatite and Hypoxia on Chondrogenesis and Hypertrophy in 3D Bioprinted ADMSC Laden Constructs. ACS Biomaterials Science \& Engineering 2017, 3 (5), 826-835.

111. Haberstroh, K.; Ritter, K.; Kuschnierz, J.; Bormann, K.-H.; Kaps, C.; Carvalho, C.; Mülhaupt, R.; Sittinger, M.; Gellrich, N.-C., Bone repair by cell-seeded 3D-bioplotted composite scaffolds made of collagen treated tricalciumphosphate or tricalciumphosphate-chitosan-collagen hydrogel or PLGA in ovine critical-sized calvarial defects. Journal of Biomedical Materials Research Part B: Applied Biomaterials 2010, $93 B$ (2), 520-530.

112. Wei, L.; Wu, S.; Kuss, M.; Jiang, X.; Sun, R.; Reid, P.; Qin, X.; Duan, B., 3D printing of silk fibroin-based hybrid scaffold treated with platelet rich plasma for bone tissue engineering. Bioactive Materials 2019, 4, 256-260.

113. Clarke, B., Normal bone anatomy and physiology. Clin J Am Soc Nephrol 2008, 3, 131139. 
114. Habibovic, P.; Barralet, J. E., Bioinorganics and biomaterials: Bone repair. Acta Biomaterialia 2011, 7 (8), 3013-3026.

115. Ha, S.-W.; Jang, H. L.; Nam, K. T.; Beck, G. R., Nano-hydroxyapatite modulates osteoblast lineage commitment by stimulation of DNA methylation and regulation of gene expression. Biomaterials 2015, 65, 32-42.

116. Levingstone, J. T.; Herbaj, S.; Dunne, J. N., Calcium Phosphate Nanoparticles for Therapeutic Applications in Bone Regeneration. Nanomaterials 2019, 9 (11).

117. Uskoković, V.; Batarni, S. S.; Schweicher, J.; King, A.; Desai, T. A., Effect of calcium phosphate particle shape and size on their antibacterial and osteogenic activity in the delivery of antibiotics in vitro. ACS applied materials \& interfaces 2013, 5 (7), 2422-2431.

118. Xu, S.; Liu, J.; Zhang, L.; Yang, F.; Tang, P.; Wu, D., Effects of HAp and TCP in constructing tissue engineering scaffolds for bone repair. Journal of Materials Chemistry B 2017, $5(30), 6110-6118$.

119. Ogose, A.; Hotta, T.; Kawashima, H.; Kondo, N.; Gu, W.; Kamura, T.; Endo, N., Comparison of hydroxyapatite and beta tricalcium phosphate as bone substitutes after excision of bone tumors. Journal of Biomedical Materials Research Part B: Applied Biomaterials 2005, $72 B$ (1), 94-101.

120. Jin, Y.; Liu, X.; Liu, H.; Chen, S.; Gao, C.; Ge, K.; Zhang, C.; Zhang, J., Oxidative stressinduced apoptosis of osteoblastic MC3T3-E1 cells by hydroxyapatite nanoparticles through lysosomal and mitochondrial pathways. RSC Advances 2017, 7 (21), 13010-13018. 
121. Shi, Z.; Huang, X.; Cai, Y.; Tang, R.; Yang, D., Size effect of hydroxyapatite nanoparticles on proliferation and apoptosis of osteoblast-like cells. Acta Biomaterialia 2009, 5 (1), 338-345.

122. Gerhardt, L.-C.; Boccaccini, A. R., Bioactive Glass and Glass-Ceramic Scaffolds for Bone Tissue Engineering. Materials (Basel) 2010, 3 (7), 3867-3910.

123. Jones, J. R., Review of bioactive glass: From Hench to hybrids. Acta Biomaterialia 2013, $9(1), 4457-4486$.

124. Gaharwar, A. K.; Mihaila, S. M.; Swami, A.; Patel, A.; Sant, S.; Reis, R. L.; Marques, A. P.; Gomes, M. E.; Khademhosseini, A., Bioactive Silicate Nanoplatelets for Osteogenic Differentiation of Human Mesenchymal Stem Cells. Advanced Materials 2013, 25 (24), 33293336.

125. Gonçalves, G.; Vila, M.; Portolés, M.-T.; Vallet-Regi, M.; Gracio, J.; Marques, P. A. A. P., Nano-Graphene Oxide: A Potential Multifunctional Platform for Cancer Therapy. Advanced Healthcare Materials 2013, 2 (8), 1072-1090.

126. Jo, H.; Sim, M.; Kim, S.; Yang, S.; Yoo, Y.; Park, J. H.; Yoon, T. H.; Kim, M. G.; Lee, J. Y., Electrically conductive graphene/polyacrylamide hydrogels produced by mild chemical reduction for enhanced myoblast growth and differentiation. Acta Biomater 2017, 48, 100-109.

127. Domazetovic, V.; Marcucci, G.; Iantomasi, T.; Brandi, M. L.; Vincenzini, M. T., Oxidative stress in bone remodeling: role of antioxidants. Clin Cases Miner Bone Metab 2017, 14 (2), 209216. 
128. Lee, W. C.; Lim, C. H. Y. X.; Shi, H.; Tang, L. A. L.; Wang, Y.; Lim, C. T.; Loh, K. P., Origin of Enhanced Stem Cell Growth and Differentiation on Graphene and Graphene Oxide. $A C S$ Nano 2011, 5 (9), 7334-7341.

129. Ehret, C.; Aid-Launais, R.; Sagardoy, T.; Siadous, R.; Bareille, R.; Rey, S.; Pechev, S.; Etienne, L.; Kalisky, J.; de Mones, E.; Letourneur, D.; Amedee Vilamitjana, J., Strontium-doped hydroxyapatite polysaccharide materials effect on ectopic bone formation. PloS one 2017, 12 (9), e0184663-e0184663.

130. Luo, Y.; Lode, A.; Akkineni, A. R.; Gelinsky, M., Concentrated gelatin/alginate composites for fabrication of predesigned scaffolds with a favorable cell response by 3D plotting. RSC Advances 2015, 5 (54), 43480-43488.

131. Castro, N. J.; O’Brien, J.; Zhang, L. G., Integrating biologically inspired nanomaterials and table-top stereolithography for 3D printed biomimetic osteochondral scaffolds. Nanoscale 2015, 7 (33), 14010-14022.

132. Khang, G., Handbook of Intelligent Scaffolds for Tissue Engineering and Regenerative Medicine. Jenny Stanford Publishing: 2017.

133. Langelaan, M. L. P.; Boonen, K. J. M.; Rosaria-Chak, K. Y.; van der Schaft, D. W. J.; Post, M. J.; Baaijens, F. P. T., Advanced maturation by electrical stimulation: Differences in response between $\mathrm{C} 2 \mathrm{C} 12$ and primary muscle progenitor cells. Journal of Tissue Engineering and Regenerative Medicine 2011, 5 (7), 529-539. 
134. Lee, S.-J.; Zhu, W.; Nowicki, M.; Lee, G.; Heo, D. N.; Kim, J.; Zuo, Y. Y.; Zhang, L. G., 3D printing nano conductive multi-walled carbon nanotube scaffolds for nerve regeneration. Journal of Neural Engineering 2018, 15 (1), 016018.

135. Cha, C.; Shin, S. R.; Annabi, N.; Dokmeci, M. R.; Khademhosseini, A., Carbon-Based Nanomaterials: Multifunctional Materials for Biomedical Engineering. ACS Nano 2013, 7 (4), 2891-2897.

136. Ilic, D.; Moix, T.; Lambercy, O.; Sache, L.; Bleuler, H.; Ohta, M.; Augsburger, L., Measurement of elastic properties of blood vessels. Conference proceedings: Annual International Conference of the IEEE Engineering in Medicine and Biology Society. IEEE Engineering in Medicine and Biology Society. Annual Conference 2005, 6, 6199-202.

137. Dönmez Güngüneş, Ç.; Şeker, Ş.; Elçin, A. E.; Elçin, Y. M., A comparative study on the in vitro cytotoxic responses of two mammalian cell types to fullerenes, carbon nanotubes and iron oxide nanoparticles. Drug and Chemical Toxicology 2017, 40 (2), 215-227.

138. Gurunathan, S.; Kang, M.-H.; Jeyaraj, M.; Kim, J.-H., Differential Cytotoxicity of Different Sizes of Graphene Oxide Nanoparticles in Leydig (TM3) and Sertoli (TM4) Cells. Nanomaterials 2019, 9 (2).

139. Liu, X.; Yang, Z.; Sun, J.; Ma, T.; Hua, F.; Shen, Z., A brief review of cytotoxicity of nanoparticles on mesenchymal stem cells in regenerative medicine. Int J Nanomedicine 2019, 14, 3875-3892. 
140. Godar, D. E.; Gurunathan, C.; Ilev, I., 3D Bioprinting with UVA1 Radiation and Photoinitiator Irgacure 2959: Can the ASTM Standard L929 Cells Predict Human Stem Cell Cytotoxicity? Photochemistry and Photobiology 2019, 95 (2), 581-586.

141. Chen, D. X. B., Extrusion Bioprinting of Scaffolds for Tissue Engineering Applications. Springer International Publishing: 2018.

142. Chen, M.; Qin, X.; Zeng, G., Biodegradation of Carbon Nanotubes, Graphene, and Their Derivatives. Trends in Biotechnology 2017, 35 (9), 836-846.

143. Castro, N. J.; Meinert, C.; Levett, P.; Hutmacher, D. W., Current developments in multifunctional smart materials for 3D/4D bioprinting. Current Opinion in Biomedical Engineering 2017, 2, 67-75.

144. Li, Y. C.; Zhang, Y. S.; Akpek, A.; Shin, S. R.; Khademhosseini, A., 4D bioprinting: the next-generation technology for biofabrication enabled by stimuli-responsive materials. Biofabrication 2016, 9 (1), 012001.

145. Sydney Gladman, A.; Matsumoto, E. A.; Nuzzo, R. G.; Mahadevan, L.; Lewis, J. A., Biomimetic 4D printing. Nature Materials 2016, 15 (4), 413-418.

146. Betsch, M.; Cristian, C.; Lin, Y.-Y.; Blaeser, A.; Schöneberg, J.; Vogt, M.; Buhl, E. M.; Fischer, H.; Duarte Campos, D. F., Incorporating 4D into Bioprinting: Real-Time Magnetically Directed Collagen Fiber Alignment for Generating Complex Multilayered Tissues. Advanced Healthcare Materials 2018, 7 (21), 1800894. 


\section{For table of contents use only}

Hydrogel-colloid composite bioinks for targeted tissue-printing

Raphaël Michel and Rachel Auzély-Velty

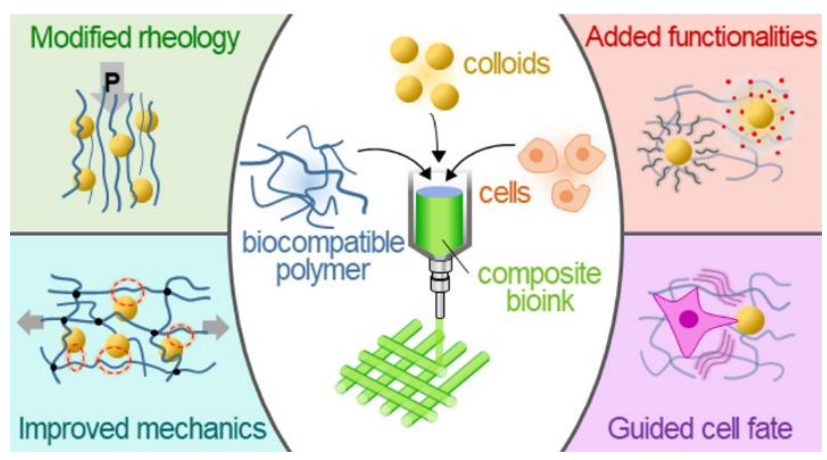

